Review

\title{
Versatility of Reverse Micelles: From Biomimetic Model to Nano(Bio)Sensors Design
}

\author{
Melania-Liliana Arsene ${ }^{1}$, Ana-Maria Gurban', Maria-Luiza Jecu' ${ }^{1}$ and Mihaela Doni ${ }^{1, *}$ \\ 1 National Institute for Research \& Development in Chemistry and Petrochemistry - ICECHIM, \\ Biotechnology Department, 202 Spl. Independentei, sector 6, Bucharest, ROMANIA, \\ melania_arsene@icechim.ro ; amgurban@yahoo.com ; jecu.luiza@icechim.ro; mihaela.badea@icechim.ro \\ * Correspondence: mihaela.badea@icechim.ro; Tel.: +40-213-163-063
}

\begin{abstract}
This paper presents an overview of the principal structural and dynamics characteristics of reverse micelles (RMs) in order to highlight their structural flexibility and versatility, along with the possibility to modulate their parameters in a controlled-manner. The multifunctionality in a large range of different scientific fields is exemplified in two distinct directions: a theoretical model for mimicry of biological microenvironment and practical application in the field of nanotechnology and nano-based sensors. RMs represents a convenient experimental approach that limits the drawbacks of the conventionally biological studies in vitro, while the particular structure confers them the status of simplified mimics of cells by reproducing a complex supramolecular organization in an artificial system. The biological relevance of RMs is discussed in some particular cases referring to the confinement and crowding environment, molecular dynamics of water and cell membrane structure. The use of RMs in different range of applications seems to be more promising due to their structural and compositional flexibility, a high efficiency and selectivity being achieved. The advance in nanotechnology is based on developing new methods of nanomaterials synthesis and deposition. This review highlighting the advantages of using RMs in synthesis of nanoparticles with specific properties and in nano (bio)sensors design.
\end{abstract}

Keywords: reverse micelles, biomimetic, confinement, water dynamics, nanoparticles, nano(bio) sensors

\section{Introduction}

A wide variety of biochemical events, from macromolecular recognition to biocatalysis associated [1] with biological systems, e.g. lipid layers, membranous organelles and interior of macromolecular chaperons [2], takes place in nano-restricted environments delimited by membranes like cells and/or cellular compartments [3]. In conjunction with the confinement effect, interactions with the structure of membrane interface have an essential influence upon in vivo molecules of water [4], conferring them special properties in terms of structural organization and dynamics.

Reverse micelles (RMs) consist of nanoscopically droplets of water delimited by a dynamic, but well-defined surfactant layer and uniformly dispersed within a non-polar organic solvent. As experimental approach, reverse micelles (RMs) represent an adequate and convenient molecular assembly at nano-scale, with controllable experimental parameters $[5,6]$.

They provide an artificial system that fulfills many of the requirements for a life-mimicking system, such as nanoscopically structures, volume-restricted environments, interactions with a membrane-like interface etc. RMs are optically clear solutions, characterized by macroscopic homogeneity but with a microscopically heterogeneous structure. Compared to bulk water, water inside cell experience an entirely different medium largely reflected by its properties, and therefore in vitro cell models have been proposed to understand the properties of water in confined conditions.

On the other hand, RMs were proposed as experimental media for synthesis of a large variety of nano-particles and for development of nano-materials. A large variety of nanostructures have 
been synthesized using reverse micelles, being taken into consideration a number of factors for selecting an appropriate surfactant for a specific synthesis reaction in reverse micelles. Since, reverse micelles are globular aggregates which are formed by the self-assembled surfactants in nonpolar solvents, many different self-assembled structures can be achieved by changing the compositions. Thus, it can be obtained spheres, cylinders or interconnected cylinders and lamellar phase micelle structures. Many of these possible nanostructures have been reported in literature as being grown inside of these shaped templates.

Synthesis of nanoparticles in reverse micelles microemulsions was proved to be an useful route in principal due to possibility to control the particles size which ensure a narrow particles size distribution, but also to a high degree of homogeneity in terms of concentration and morphology.

\section{Fundaments of Reverse Micelles}

\subsection{Reverse micelles microemulsion}

RMs are formed in various ternary mixtures composed from surfactant-polar phase-non-polar solvent in different combinations and ratios. They result by spontaneous self-assembly of the surfactant molecules in non-polar organic solvents, without requesting any high inputs of energy or shear conditions ("dry micelles"). In the presence of water or other polar solvent, RMs aggregates lead to uptake these molecules inside the hydrophilic internal region of the two-component cluster and forming in this way isolated droplets uniformly dispersed in the bulk solvent ("swollen micelles") [7].

Generally, different isotropic or non-isotropic ternary systems result by mixing together amphiphilic molecules of surfactant (SURFace ACTive AgeNT) with two immiscible solvents, commonly referred to as oil, term used liberally to refer to any non-polar water-insoluble solvent, and water, term describing any polar water-soluble solvent [8]. According to Danielsson and Lindman [9], the thermodynamically stable isotropic liquids obtained from this mixture usually are defined as "microemulsion" and are composed of one or more phases which coexist separately, but are in balance with each other [10], e.g. water continuous (oil-in-water), oil continuous (water-inoil), bicontinuous (middle phase) [11]. The scientific recognition of microemulsion dates from 1943 (Hoar and Schulman)[12], but the term was first used by the latter author only in 1959 to describe the transparent solution of the multiphase system formed by water/oil/surfactant (w/o/s) mixture [13].

In the ternary system phases, the surfactant molecules can be aggregate into micelles or closed structures, such as normal or reverse micelles, but also they are able to associate into either extended flat lamellae with plane-like structures (lamellar or L-phases) which correspond to smectic liquid crystalline phases, as well as distorsed and interconnected lamellae with a sponge-like structure (flat bilayer L3-phase) corresponding to bicontinuous phase [14].

Number and description of the phases can be graphically highlighted by the construction of a Gibb's phase diagram, each corner of the equilateral triangle representing $100 \%$ concentration of water, oil and surfactant, respective [14]. Keeping concentration of one component constant and varying the concentrations of the other 2 components, it can be visualized the range of composition that correspond to the interest phase ( $\mathrm{L}_{1}$ for normal micelle, $\mathrm{L}_{2}$ for reverse micelle, w/o phase, $\mathrm{o} / \mathrm{w}$ phase, optically isotropic microemulsion regions, birefringent phases) [15].

\subsection{Formation of Reverse Micelles Microemulsions}

Molecular base of RMs microemulsion formation is set on the particular capacity of surfactant to be adsorbed spontaneously at the free interface between oil and water. The pelicular property is associated with the amphiphilic structure of surfactants, that confers them a dual affinity: for the hydrophilic groups from polar phase, and respectively, for the hydrophobic groups from apolar phase, respective [16]. It is assumed that repulsive forces are characterizing the interactions between oil and water and the absence of cohesiveness at molecular level generates tension at $t$ $(\mathrm{w} / \mathrm{o} / \mathrm{s})$ he interface $\mathrm{o} / \mathrm{w}$, known as surface tension $(\gamma$, expressed in $\mathrm{mN} / \mathrm{m})$ [17]. The presence of 
surfactant molecules modifies the nature of the forces from repulsive towards attractive and minimize the contact area due to their pelicular ability, reflected in the decreasing of $\gamma$ value below $10^{-2} \mathrm{mN} / \mathrm{m}[11,18]$. The resulting interfacial energy is exceeded by dispersion entropy and thus the dispersion process is facilitated.

Different basic considerations have been proposed in order to explain the formation and the stability of microemulsions, being concretized in three theories [19]:

(i) Interfacial/mixed film theory assumes that the spontaneous formation is the result of a complex dual film constituted at $\mathrm{o} / \mathrm{w}$ interface, thus the tension cumulated in this region decreased to zero at equilibrium. A negative transient interfacial tension, describing the tendency of spontaneous expanding of interface, has been postulated in this theory suggested by Schulman [12];

(ii) Solubilization theory proposed by Gillberg treats microemulsion as thermodynamically stable monophasic solution of water-swollen micelles (RMs solubilizing water) or oil-swollen micelles (normal micelles solubilizing oil). The author also states the relationship between RMs and w/o microemulsions with the help of phase diagrams [20];

(iii) Thermodynamic theory proposed by Paul and Moulik correlates the process of microemulsion formation with the value of the free energy of the system formed by mixing one phase into another. According to this theory, the resulted negative value will govern the microemulsification process in a spontaneous and thermodynamically stable way $[21,22]$.

Besides the basic premise for micellization process, a quantitative condition also is requested for self-assemble surfactant molecules. At low concentrations, surfactant molecules exist independently in solution or are discretely arranged on the o/w surface, while the surface tension is insignificant modified. The increasing of surfactant concentration is accomplished by addition of more molecules on the $\mathrm{o} / \mathrm{w}$ surface and considerable decrease of the surface tension of the solution. This tendency is kept until the surface becomes saturated, and the formation of the micelles is initiated and at that point the surface tension will no longer change (Figure 1). The concentrationdependent parameter is expressed as critical micellar concentration (CMC), defining the minimum concentration of the surfactant necessary for micelles formation [11]. It represents the concentration of free or aggregated surfactant molecules in equilibrium with those forming micelles and is characteristic for each surfactant and ternary system [23,24].

\section{Surfactant concentration}

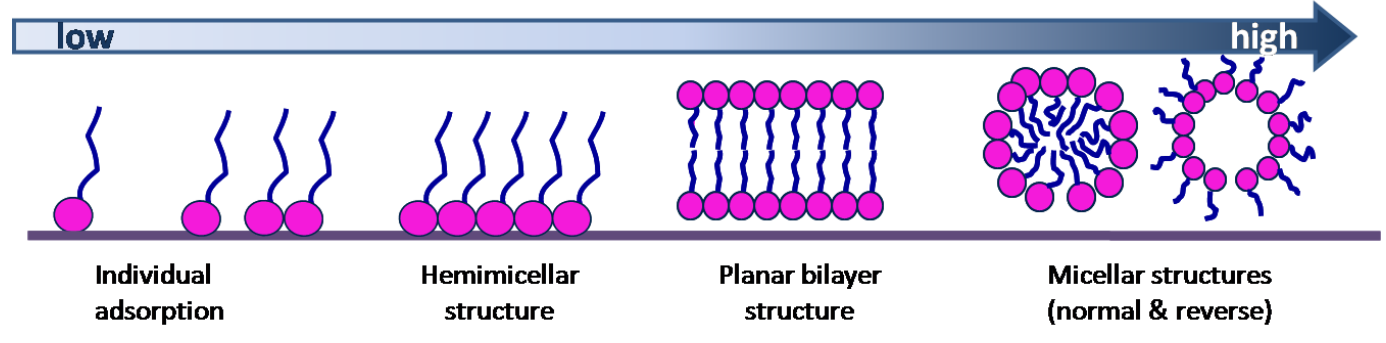

Figure1. Concentration influence on typical surfactant structures at the water-oil interface

\section{Surfactant Characterization}

\subsection{Interfacial film of surfactant}

Properties of water droplets shielded by surfactant monolayer in RMs, such as size, shape, polydispersity and interactions, are governed by the elastic particularities of the interfacial surface, in terms of a preferred spontaneous curvature, e.g., radius of curvature, and film stiffness, e.g., constants of rigidity for mean and total (Gaussian) curvature that characterizes the bending of the surface [11].

The preferred curvature, $C_{0}$, defined as the difference between the areas occupied by hydrophilic head and lipophilic tails, is classified by convention in positive curvature (toward oil corresponding to a prevalent hydrophilic part) (for $\mathrm{o} / \mathrm{w}$ systems) and negative curvature (toward 
water corresponding to a prevalent lipophilic part) (for w/o systems) respective [4]. The ratio between the radius of the droplets and the radius of spontaneous curvature is correlated with the minimum or "critical" radius of curvature $\left(R_{c}\right)$, which anticipates the shape of aggregates (Figure 2). Direction and extent of the curvature of the adsorbed interfacial film depends on the composition of the phases it separates and on surfactant type.

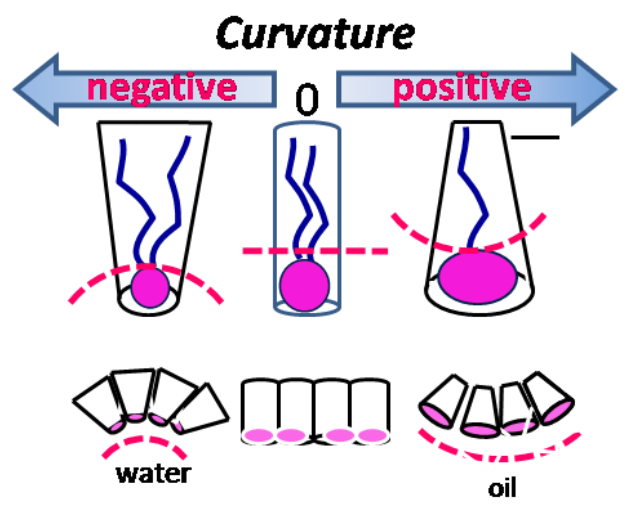

Figure 2. Correlation between the type of curvature and surfactant morphology

The amphiphilic structure of surfactant, which is the critical property for micellisation capacity, is described by the hydrophilic-lipophilic balance (HLB), which suggests the type of microemulsion to be form, e.g., w/o microemulsion for HLB value $<10$ (predominantly hydrophobic surfactants) and o/w microemulsion for HLB value $>10$ (predominantly hydrophilic surfactant) [19]. This concept relates the molecular structure to elastic properties, such as interfacial packing and film curvature, and empirically expressed the relative proportions of hydrophilic and hydrophobic groups within the molecule of surfactant [25].

Israelachvili stated in the 1970's the concept of molecular packing parameters which affords a simple, intuitive and predicting approach of self-assembly process based on the contribution of surfactant head groups [26], while Nagarajan has completed this concept by emphasizing the controlling role of tails in predicting the shape and size of equilibrium aggregates [27].

The overall packing shape of surfactant molecules is conveniently described by a geometric parameter, namely critical packing parameter (CPP), a dimensionless number, and can be calculated according to the formula:

$\mathrm{CPP}=\mathrm{V} /\left(\mathrm{a} . \mathrm{lc}_{\mathrm{c}}\right)$

where,

ao is the surface area of head groups per molecule and is the result of repulsive hydrophilic forces between them and attractive hydrophobic forces from the hydrocarbon-water interface;

$\mathrm{V}$ is the effective hydrocarbon volume resulting from chain-chain repulsive steric forces and oil-penetration interactions;

$l_{c}$ is the length of the fully extended chain which limited the thickness of hydrocarbon layer.

Table 1 summarizes the correlation between the structure of surfactants (e.g., headgroup and tails, geometry of surfactant molecule), interfacial film characteristics (e.g., curvature, CPP values) and the type of critical packing shape of surfactant [19, 25-30].

\subsection{Surfactant Types}

The quantitative weight of surfactants in the ternary mixtures does not represent the most important contribution to the overall properties of the RMs [31] (e.g., size and shape of water droplets, polydispersity and droplets interactions), their major role being conferred by the elastic properties of the interfacial layer (Figure 3). Most RM systems can be prepared using different surfactants with ionic (anionic and cationic) and non-ionic (in which case they can be zwitterionic or dipolar) chemical structures depending on the nature of the hydrophilic and hydrophobic groups. 
Tabel 1. Relationship between molecular structure and characteristics of surfactant and the corresponding phase type

\begin{tabular}{|c|c|c|c|c|c|c|c|}
\hline $\begin{array}{l}\mathrm{CPP} \\
\text { range }\end{array}$ & $\begin{array}{c}\text { Area of } \\
\text { surfactant } \\
\text { headgroup }\end{array}$ & $\begin{array}{l}\text { Volume } \\
\text { of } \\
\text { surfactant } \\
\text { tail }\end{array}$ & $\begin{array}{l}\text { Geometric } \\
\text { shape of } \\
\text { surfactant }\end{array}$ & Curvature & $\begin{array}{c}\text { Structures of } \\
\text { surfactant } \\
\text { aggregates }\end{array}$ & $\begin{array}{c}\text { Phase } \\
\text { structure }\end{array}$ & $\begin{array}{l}\text { Phase } \\
\text { type }\end{array}$ \\
\hline$\leq 0.33$ & Very large & $\begin{array}{c}\text { Reduced } \\
\text { (single- } \\
\text { chain) }\end{array}$ & Cone & $\begin{array}{l}\text { High } \\
\text { positive }\end{array}$ & $\begin{array}{l}\text { Spherical or } \\
\text { ellipsoidal } \\
\text { micelles }\end{array}$ & $\begin{array}{l}\text { Normal } \\
\text { micellar }\end{array}$ & $\mathrm{L}_{1}$ \\
\hline $0.33-0.5$ & Smaller & $\begin{array}{l}\text { Small } \\
\text { (single } \\
\text { chain) }\end{array}$ & $\begin{array}{l}\text { Truncated } \\
\text { cone }\end{array}$ & $\begin{array}{l}\text { Medium } \\
\text { positive }\end{array}$ & $\begin{array}{l}\text { Extended } \\
\text { micelles } \\
\text { (rod-like } \\
\text { structures) or } \\
\text { large } \\
\text { cylindrical }\end{array}$ & Hexagonal & $\mathrm{H}_{1}$ \\
\hline $0.5-1$ & Large & $\begin{array}{l}\text { Large } \\
\text { (double- } \\
\text { chains) }\end{array}$ & $\begin{array}{l}\text { Truncated } \\
\text { cone }\end{array}$ & $\begin{array}{l}\text { Low } \\
\text { positive }\end{array}$ & $\begin{array}{c}\text { Flexible } \\
\text { bilayers and } \\
\text { vesicles }\end{array}$ & Bicontinuous & $\mathrm{V}_{1}$ \\
\hline$\sim 1$ & Small & $\begin{array}{l}\text { Small/ } \\
\text { medium } \\
\text { (double } \\
\text { chains) }\end{array}$ & Cylinder & $\begin{array}{l}\text { Zero or } \\
\text { planar }\end{array}$ & $\begin{array}{l}\text { Lamellae or } \\
\text { planar bilayers }\end{array}$ & Lamellar & Lo \\
\hline \multirow[t]{3}{*}{$>1$} & Small & $\begin{array}{l}\text { Large } \\
\text { (double- } \\
\text { chains) }\end{array}$ & $\begin{array}{l}\text { Inverted } \\
\text { truncated } \\
\text { cone or } \\
\text { wedge }\end{array}$ & $\begin{array}{l}\text { Negative or } \\
\text { reverted }\end{array}$ & $\begin{array}{c}\text { Inverted } \\
\text { structures } \\
\text { - } \quad \text { cubic }\end{array}$ & $\begin{array}{l}\text { Inversed bi- } \\
\text { continuous }\end{array}$ & $\mathrm{V}_{2}$ \\
\hline & & & & & - hexagonal & $\begin{array}{l}\text { Inverse } \\
\text { hexagonal }\end{array}$ & $\mathrm{H}_{2}$ \\
\hline & & & & & - micellar & $\begin{array}{l}\text { Reverse } \\
\text { (inverted) } \\
\text { micelles }\end{array}$ & $\mathrm{L}_{2}$ \\
\hline
\end{tabular}




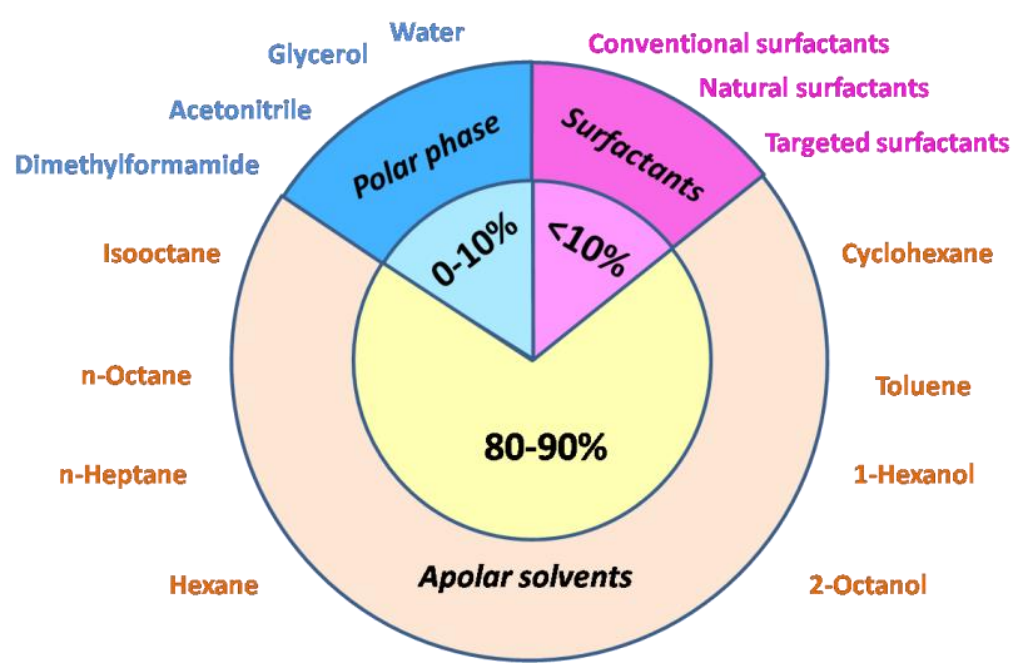

Figure 3. Relative proportion of components in a reverse micellar system

\subsubsection{Conventional surfactants}

Ionic surfactants. The mostly used surfactants to prepare RM are anionic surfactants [10,31], which include sodium bis(diethyl hexyl) phosphate(NaDEHP), calcium dodecyl sulfate (CDS) and sodium dodecyl sulphate (SDS), but in most of the studies the first choice for surfactants of any nature is AOT (sodium bis(2-ethyl hexyl) sulfosuccinate), also known as Docusate sodium (dioctyl sodium sulfosuccinate).

AOT (Aerosol Orange T or Aerosol OT) is an anionic surfactant with branched twin alkyl chains and a single head group (the anionic sulfonate), $\mathrm{Na}^{+}$being the usual counterion $[2,31]$. From chemical point of view it is an ester of sulfosuccinate acid $\left(\mathrm{C}_{20} \mathrm{H}_{37} \mathrm{NaO}_{7} \mathrm{~S}\right)$, having three possible rotamers, but only one with appropriate stereochemistry for most stable conformation of surfactant in apolar solvents [32]. The geometry of AOT molecule is wedge-like shape, with the polar group sitting at the small cross section, and will therefore favor aggregates in which the surfactant molecules can keep their concave curvature.

The AOT-RMs are significant monodispersed and are spherical, retaining the shape over a wide range of water content ( $w_{0}$ from 0 to 60 ) while the size range from radii of less than $1 \mathrm{~nm}$ to radii up to $14 \mathrm{~nm}$.

The special attention received by AOT is related with particular characteristics of the RM formed, e.g., enhances the capacity to solubilize large quantities (up to 400,000 molecules) of water inside the cluster and does not need a co-surfactant presence [33] (Figure.4a). The unusual efficiency is attributed to the relationship between structure and property, with special mention to the inverted truncated cone-shape and well-balanced structure of molecule [34].

The cationic group of surfactants with relevance for RM formation usually belongs to quaternary ammonium alkyl salts, e.g., alkyl ammonium halides and tetraalkyl ammonium halides. The most used in different studies and applications is cetyltrimethylammonium bromide (CTAB), but other cationic surfactants can also be use, e.g., cetylbenzyldimethylammonium chloride (CBAC), benzyl dodecyl bis(hydroxyethyl) ammonium chloride (BDBAC), didodecyldimethylammonium bromide (DDAB), tetradecyl trimethyl ammonium bromide (TTAB), trioctyl methyl ammonium chloride (TOMAC), cetyl pyridinum bromide (CPB) and sodium dodecylbenzenesulfonate (NaDBS) [10, 35, 36].

Non-ionic surfactants. RMs formed with non-ionic surfactants have extreme sensitivity to the process conditions and therefore are less characterized [10, 31]. However, different surfactants from Tween, Triton (e.g., Triton X-100 [polyoxyethylene(10)isooctylphenyl ether], Brij (e.g., Brij30 polyoxyethylene(4) lauryl ether), Span series as well as Igepal CO520 or various mixtures of polyoxyethylene(5) nonylphenol ether (NP-5),polyoxyethylene(9) nonylphenol ether (NP-9) and polyoxyethylene(12) nonylphenol ether (NP-12) are used in various studies [31, 37, 38]. 
Mixed surfactants composition. The simultaneous presence of an ionic and non-ionic surfactant conduct to the formation of mixed RMs and is specially proposed in order to reduce some drawbacks encountered in the case of each surfactant component alone, for instance to modify the polarity of the surfactant film and implicit of its surrounding microenvironment [31]. Exemplary mixed RMs are usually contain the well known anionic surfactant AOT together with either Span 60 [35], Tween 85 [39], Brij 30 [40, 41] or the cationic surfactant CTAB with Tween 80 or Triton X-100 [41].

Besides synthetic surfactants, some bile salts such as sodium taurocholate (NaTC), 3-[(3cholamidopropyl)dimethylammonio]-1-propanesulfonate hydrate (CHAPS) and sodium cholate (SC) can participate to form mixed RM systems together with ionic surfactants, mostly with AOT [42].

\subsubsection{Natural surfactants}

Molecules with surface-active properties are naturally found in biological systems, mainly as secondary metabolites, and have a diverse range of chemical structures. These natural surfactants or biosurfactants usually of microbial origin can replace the conventional surfactants in RM composition, showing much less negative effects to the environment and potential contribution to generate green applications due to their non-toxic nature and biodegradability [43]. Glycolipids, as long-chain aliphatic acids or hydroxyaliphatic acids, are known non-ionic biosurfactant compounds, the most important members being rhamnolipids [44] produced by Pseudomonas aeruginosa, trehalolipids produced by Rhodococcus erythopolis, sophorolipids produced by Candida bombicola [45].

\subsubsection{Targeted surfactants}

Affinity surfactants. Selective capacity of RM in extraction and separation applications can be increase especially by affinity interactions resulting from the presence of affinity ligands in the interfacial film formed by the usually ionic or non-ionic surfactants. An affinity ligand as di(2ethylhexyl) phosphoric acid is used to formulate RMs together with two non-ionic surfactants (Triton X-45 and Span 80)[46], while a sugar-binding affinity ligand as lectin concanavalin A (conA) can be introduced in addition of the anionic AOT surfactant [31,47].

Another approach for improving the selective characteristics of RM is represented by direct modification of the surfactant structure. In this way, the non-ionic Span 85 was modified with a widely used dye-ligand affinity chromatography, Cibacron Blue F3GA, having structural similarity to natural ligands. The affinity of the CB-Span 85 conjugate is directed to proteins with cofactor binding domains and the corresponding RMs are considered to have promising potential in biotechnological area [48].

New surfactants. Despite the large ranging of available commercial surfactants, the broadening of application domains and increasing expectations reported to RM performance have conducted to the design and synthesis of surfactants according to the new research requests [31]. Such two new surfactants with relevance in development of innovative applications have been proposed by Goto et al., namely di(tridecyl) phosphoric acid (DTDPA) and dioleyl phosphoric acid (DOLPA), their hydrophobic structure being adjusted in order to improve the characteristics of RM systems for protein extraction [49].

\subsubsection{Co-surfactants}

In many cases, the use of a single chain surfactant is not sufficient to reduce the $\mathrm{o} / \mathrm{w}$ interfacial tension below $10^{-2} \mathrm{mN} / \mathrm{m}$ in order to compensate the dispersion entropy, fact which may lead to an inefficient formation and/or stability of RMs. To overcome these inconveniences, addition of a second surfactant with low molecular weight is needed in order to decrease the bending factor of the layer of surfactant and to enhance the thermodynamic stability. The amphiphilic nature of cosurfactant allows its accumulation mostly at the interfacial layer followed by the incorporation of 
co-surfactants molecules into the layer formed by the main surfactant. The proposed mechanism of their action suggests a buffer action of co-surfactants molecules resulting in the decrease of both electrostatic repulsive interactions between the charged head groups and hydrophobic interactions between the hydrophobic tails of the first surfactant molecules [24, 50] (FIG.4b). The effect consists in a denser packing of surfactants molecules and formation of stable inner core of RM as well in increased flexibility of the interfacial film around the droplets of RM and an enhanced interdroplets interaction [37]. On the other hand, use of co-surfactant results in the modification of the overall HLB of the system, i.e., commonly a co-surfactant with very low HLB is added to a surfactant with high HLB.

An advantage of co-surfactants use is the possibility to operate as tunable tools for the shape and diameter of RM (e.g., enlargement of micelle size formed by a cationic surfactant), but on the other hand their presence leads to a system with a higher degree of complexity, the phase diagram for four components being more difficult to obtain [50].
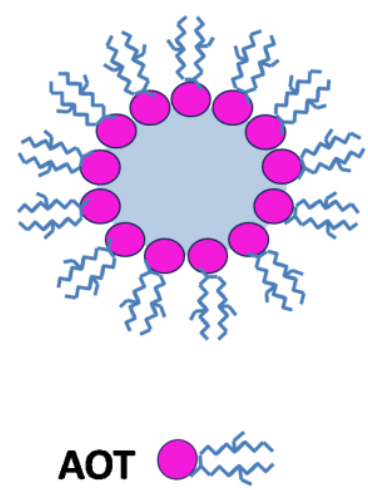

(a)

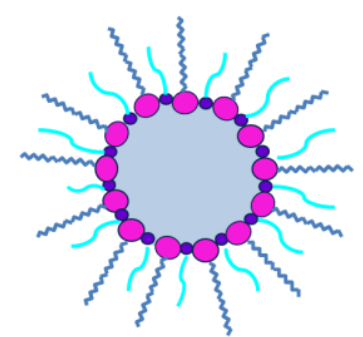

CTAB

Co-surfactant

(b)

Figure 4. Schematic cross section through (a) AOT-based RM; (b) CTAB-based RM

The efficiency of co-surfactants is correlated with their ability to penetrate the surfactant layer to a greater depth. Generally, most effective co-surfactants are short to medium chain alcohols, for example n-butanol, n-pentanol, n-hexanol, n-heptanol, n-octanol, n-decanol, isopropanol, benzyl alcohol, as well as cholesterol and in some case propylene glycol [50].

\section{Characterization of Reverse Micelles}

\subsection{Structural characterization of RMs}

Reverse micelles are composed of aggregates of surfactant molecules structured in a polar core of hydrophilic head groups while their hydrophobic tails are directed outside into the organic bulk. The concept of surfactant aggregates formation was initially proposed for aqueous medium by James William McBain in the early 1910s, while two decades later G.S. Hartley has named this concept by the term "micelle" (from the Latin "mica" which mean small particle), a term borrow from biology [51]. The term "reverse micelles" originates much later, from the 1970s, and defined the reversed/inverted situation from a normal micelle, consisting in an amphiphilic aggregate formed in a non-polar hydrophobic medium.

Reverse micelles represent dynamic formations [52] that can change surfactant molecules between them and with solvent at a high rate, the residence time of the surfactant molecule being about $10^{-7}$ s [53]. Despite the high mobility of surfactant molecules and their continuous vibration movement, the micellar interface is well defined and not permeable to organic solvents surrounding micelle aggregates [54].

Most of the structural properties of RMs are induced and controlled by the ratio between the polar phase-to-surfactant concentrations. As water is generally the polar phase used to obtain RMs, this parameter is referred as degree of hydration and is considered even more relevant to describe 
the system features than the water content [55]. It is commonly defined as the molar ratio of waterto-surfactant:

$$
\mathrm{W}_{0}=\left[\mathrm{H}_{2} \mathrm{O}\right] /[\text { Surfactant }]
$$

Geometrical considerations can be applied in the most of the cases, usually droplets being described as spherical-like structures, and a linear relationship between the average droplet radius $\mathrm{R}_{\mathrm{m}}$ and the externally controlled parameter $\mathrm{w}_{0}$ can be set: $\mathrm{R}_{\mathrm{w}}=0.175 \mathrm{w}_{0}$, while the hydrodynamic radius, $R$, contains the length of the surfactant molecule in addition to $R_{w}: R=R w+0.15[56]$.

For a particular RM containing AOT-surfactant, the relation is defined as $R_{m}(n m)=0.15 w_{0}$ +0.44 , where $0.44 \mathrm{~nm}$ represents the diameter of the dry micellar core delimited by a surfactant film with the optimal interfacial curvature [57].

Generally, the degree of hydration of RM is ranging from 1 to 50, value which can be exceeded in some particular systems, corresponding to diameter size varying from 1 to a few tens of nanometers [58]. RMs are characterized by a surprising narrow range of size distribution, the polydispersion index varying from 10 to $20 \%$ depending on the ternary system [59].

The size of RMs is a tunable parameter of the system and can be controlled by varying the values of wo, e.g. increased/decreased diameter of inside RM cavity is obtained by increasing/decreasing the water content at the same surfactant concentration or by decreasing/increasing surfactant concentration at a constant water concentration, respective [60]. Also, concentration of RMs aggregates present in bulk solvent can be change by simultaneous modification of water and surfactant concentrations, maintaining constant the wo value.

RMS are characterized by a low interfacial tension (generally less than $10^{-2} \mathrm{mN} \cdot \mathrm{m}^{-1}$ ), but with a large surface area $\left(10^{2}-10^{3} \mathrm{~m}^{2} \mathrm{~cm}^{-3}\right)$ while their nanometer size (usually not more than $100 \mathrm{~nm}$ ) confers optically transparency to the colloidal solution (Figure 5). The RM surfactant aggregates generally have smaller size compared with their counterpart hydrophilic micelles, having an aggregation number less than 50 .

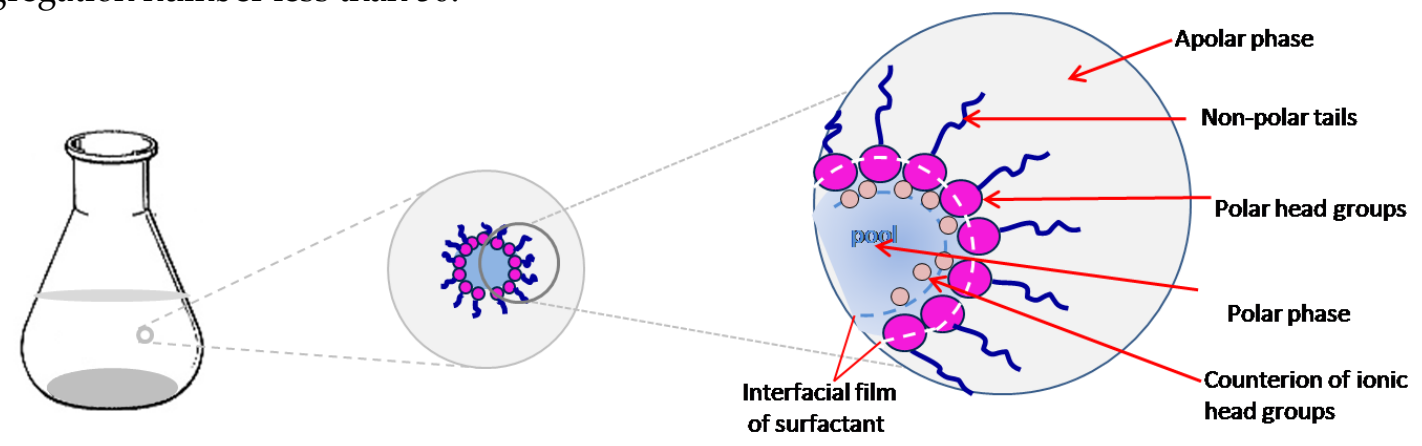

(a)

(b)

(c)

Figure 5. Schematic representation of RMs at different levels: (a) macroscopic; (b) microscopic; (c) molecular.

As a consequence of the microaqueous phase structure in the internal cavity of RMs, the effective polarity and viscosity of the intramicellar water vary radially and they differ substantially from those of the water-solvent. For example, from the fluorescence data it was concluded that the polarity of the intramicellar medium at low degrees of hydration is closer to the value for methanol, reaching values equivalent to those of bulk water only at high values $\left(\mathrm{w}_{0}=30\right)$. Regarding viscosity of intramicellar water at low $w_{o}$-values, it was found to be 200 times higher than for chloroform [61].

The nucleophilic activity of solubilized water in AOT RMs is $10^{3}$ times higher than for watersolvent [62]. The greatest reaction capacity is presented by water molecules that hydrate the polar groups of the surfactant, as well as that in the hydration layer immediately following. The subsequent water addition decreases its reaction capacity due to the formation of intermolecular hydrogen bonds. 
In contrast to normal micelles from aqueous solutions, the reverse micelles are characterized by an electrically neutral outer layer so that Coulomb rejection forces do not occur, thus making possible to frequently perform collisions [53]. It is considered that the exchange of content between RMs is a collision-fusion-fission process [63]: by collision of two RMs results a dimer containing a single aqueous nucleus obtained by the fusion of the two component nuclei and the dimer fission results in the formation of two new RMs with redistributed content [64].

\subsection{Water-pool structure}

In RM, the properties of water molecules are generally associated with the influence of the interface upon them, in particular of the surfactant heads modeled as a pair of atomic ions. Their structure inside the water-pool is described as a multilayered composition, where water-pool is the term proposed by Menger in 1973 [65, 66] and generally accepted to define the water entrapped inside the RMs.

While the usually model takes into consideration two states of water molecules [67], namely a layer located nearby the surfactant interface corresponding to the "bound" layer and the bulk-like in the interior of the water-pool considered to be the "free" form, a more complete model identified a structural heterogeneity described by three species of water molecules, the third specie of water being the molecules "trapped" at the interface of surfactant (Figure 6) [68-71].

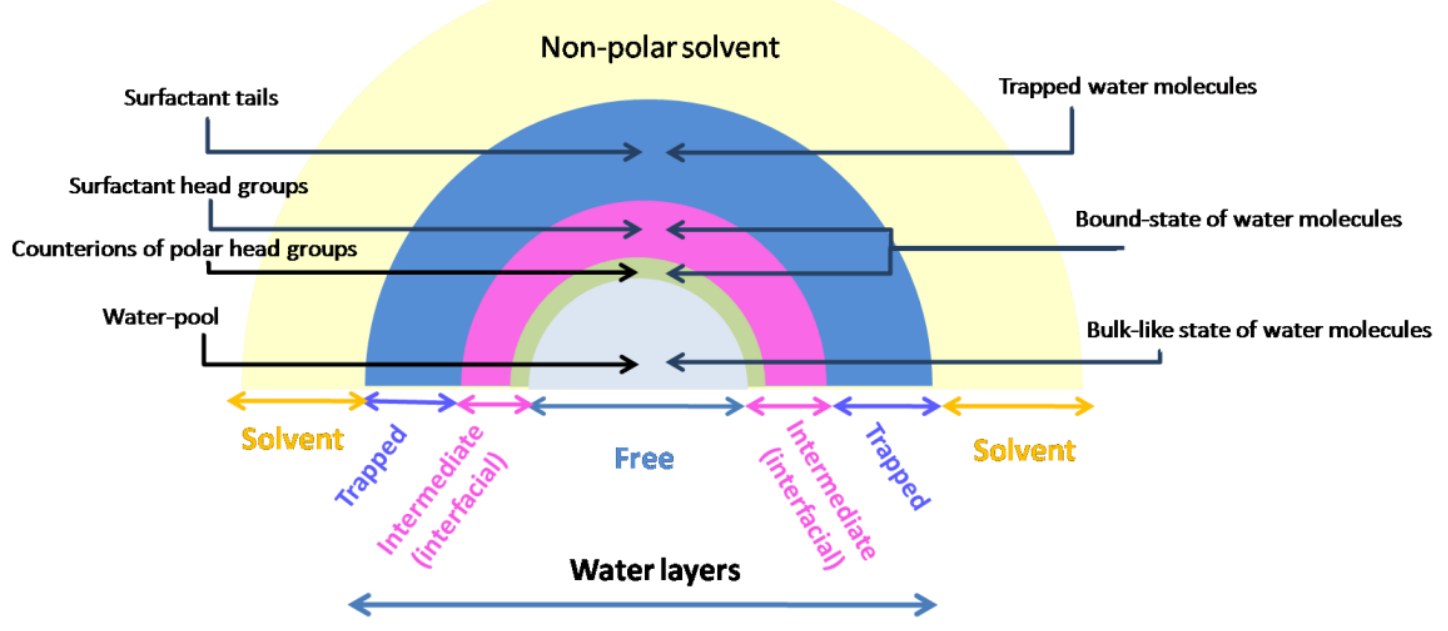

Figure 6. Correlation between the general structure of RMs and the multilayered structure of water inside RMs

The region consisting of trapped water is the nearest layer to the cavity of surfactant and is composed by molecules which are interacting directly with the large immobilized head groups of surfactant, forming cluster around them, while the H-bonds between the water molecules do not exist. In the case of AOT-RM, trapped water is coordinated with the AOT head and/or carbonyl group, about 13 trapped water molecules corresponding to one surfactant molecule [72].

The ensuing layer is located in the next neighbor of interface, where its influence is very strong, and is consisting of rigidly fixed molecules ("bound" state of water) between the charge groups of surfactant molecule (e.g. 2-3 water molecules rigidly bind by one AOT molecule). In this layer, H-bonds are settling either with the head group or other water molecules, and also interactions ion-dipole between counterions and water molecules are occurring. It results in an organization and orientation of the molecules of water in this region, corresponding to the intermediate layer in the three states model, respectively to interfacial layer in the two states model.

Being protected by the previous water layer as well as by the counterions, the water molecules from inside the water-pool of RM have an almost similar structure, but not identical, with bulk water, each molecule forming near $4 \mathrm{H}$-bonds [73]. They compose the "free" state of water in RM, 
sometimes admitted as a separate phase, and this behavior is characteristic to large size RMs (wo 216.5) where the influence of the interface is no longer so powerful in the center of RM [33].

Generally, the number of water layers in RM is directly correlated with the interface interaction strength and indirectly related to the RM size and hydration degree [74]. So different percentages of interface-interacting water are reported, ranging from $100 \%$ in very small RMs (wo $=2$ ) to $36 \%$ [33] and $25 \%$ [75] in intermediate $\mathrm{RMs} \mathrm{(} \mathrm{w}_{0}=10$ and $\mathrm{w}_{0}=16.5$ respectively), and only $8 \%$ in very large $R M s$ with $\mathrm{w}_{0}=46[75]$.

\section{3. $\mathrm{pH}$ across the water-pool}

The principal parameter usually use to characterized any aqueous system is the $\mathrm{pH}$, one of the older concept defined more than a century ago. The actual standard definition for $\mathrm{pH}$, recommended by IUPAC, is based on hydronium ion concentrations and is applied only for a range of $\mathrm{pH}$ between 2 and 12, at an ionic strength no more than $0.1 \mathrm{~mol} \mathrm{~L}^{-1}$ [76]. Based on these conditions, the minimum volume necessary to apply the conventional definition of $\mathrm{pH}$ in an aqueous solvent is determined by the dissociation of water molecules [77,78]. For instance at neutral $\mathrm{pH}$, from $10^{7}$ molecules of water only one is dissociated, but the number of water molecules in very large RMs is only about 300,000 ( $\mathrm{w}_{0}=40$ ), being even less in smaller RMs (e.g., about 30.8 molecules for $\mathrm{w}_{0}=1.5$ or 20,500 molecules for $\mathrm{w}_{0}=10.5$ ) [79]. Therefore the number of water molecules inside a RM water-pool is insufficient to have at least one hydronium ion [80,81]. This argument describes the traditional concept of $\mathrm{pH}$ as a bulk macroscopic parameter which cannot be directly applied in the case of size-limited systems with very small number of water molecules (average about $10^{3}$ ) where the effective proton concentration cannot be calculated. In addition to the above-mentioned considerations, a gradient of proton concentrations inside the water-pool is expected, related with its structural heterogeneity [76].

The conceptual problems regarding $\mathrm{pH}$ in $\mathrm{RM}$, as well as experimental difficulties related with the unenforceable use of traditional pH-meters [82], have been identified even from 1980 by Luisi \&coworkers [83] who emphasized the impossibility to determine the absolute value of $\mathrm{pH}$ in $\mathrm{RM}$ and recommended two working $\mathrm{pH}$, the $\mathrm{pH}$ inside the water-pool, defined as $\mathrm{pH}_{\text {wp }}$, and the $\mathrm{pH}$ of the starting buffer in bulk water, namely $\mathrm{pH}$ st. Arguing the major differences between the two approaches, the author suggested to treat the water inside RM as a new solvent and proposed the use of an empirical acidity scale based on measurements of ${ }^{31} \mathrm{P}$-chemical shifts of phosphate buffers [83]. In AOT-isooctane RM, the experiments reported by Luisi revealed a $\mathrm{pH}_{\mathrm{wp}} / \mathrm{pH}_{\mathrm{st}}$ difference of less than $0.4 \mathrm{pH}$ units, difference which may be variable in other cases or experimental conditions [84].

As the accuracy of the classical definition of $\mathrm{pH}$ based on proton activity is obvious at least uncertain in RM, the researchers have reoriented towards concepts like "acidity" and "basicity" which are considered to be more adequate in such systems. These concepts are associated with indirect measurements based on acidity scales of a molecular probe in a $\mathrm{pH}$-sensitive reaction and generally performed through a spectroscopic method [85], either a UV-Vis absorption based on shifts of spectral peaks or (steady-state and time resolved) fluorescence techniques using a $\mathrm{pH}$ sensitive excitation spectrum [79]. In the latter case, probe molecules presenting excited state proton transfer may be resided in different regions of water-pool [86], e.g., 2-naphthol-6,8-disulfonate sodium salt located in the free water [87] or 7-azaindole mostly present in the interfacial zone of AOT-RMs [88], and their fluorescence responses suggest/confirm the heterogeneity of water structure in RMs.

The presence of the probe molecule, even at very low concentration, can interfere with the formation and nature of RM and/or can change the overall charge during the proton transfer and/or can influence the inside environment $[89,90]$. For example, in CTAB RM, the chromophore probe molecule $\mathrm{Ru}(\mathrm{bpy}) 3^{2^{2+}}$ has affected both the water content and the distribution of droplets size [91]. All these drawbacks confer a degree of ambiguity to the assay results which can be avoided by using an alternative method as NMR to evaluate the acidity of aqueous core [92]. While ${ }^{31} \mathrm{P}$ chemical shifts, initially proposed, restrict the measurement area to the use of phosphate buffers 
inside water-pool, other magnetic resonance relaxation measurements have been proposed to measure the local proton activity in RMs. Halliday \&coworkers [84] used the effect of $\mathrm{pH}$ changes on the relaxation times ( $\mathrm{T}_{1}$ and $\mathrm{T}_{2}$ ) of the aqueous droplets inside RMs (e.g., CTAB-hexanol-water, CTAB-hexane-pentanol-water and Triton X-100-cyclohexane-hexanol-water). Baruah \&coworkers $[89,90]$ used another NMR probe, namely highly charge decavanadate $\left(\mathrm{V}_{10}\right)$ oligomer for ${ }^{51} \mathrm{~V}$ NMR spectroscopy in AOT-isooctane RMs [90]. Information obtained shows the consistent deprotonation of the probe and indicate the existence of a proton gradient inside the RM (neutral core, but acidic interface) caused by the migration of proton toward the interface and concentration of the counterions in the core of RM [93].

Besides the methods using optical $\mathrm{pH}$ sensor or molecular probe, Mukherjee \&coworkers [94] proposed the acid-catalyzed hydrolysis of sucrose [95], respectively the inversion of sucrose, reaction monitorized by the rotation of polarized light. Their study was based on two working hypothesis: (i) the neutral molecule of sucrose will be located inside the water pool; (ii) the availability of protons inside the water-pool will affect the rate of sucrose hydrolysis in micellar medium compared with the reaction rate in bulk-water. In AOT-RMs, the slowdown of the inversion rate is correlated, in agreement with ${ }^{51} \mathrm{~V}$ NMR conclusions, with a deficiency of catalyst, respectively $\mathrm{H}^{+}$, from the core, while the increased reaction rate in CTAB-RMs suggests a higher concentration of protons in this area (Figure 7).

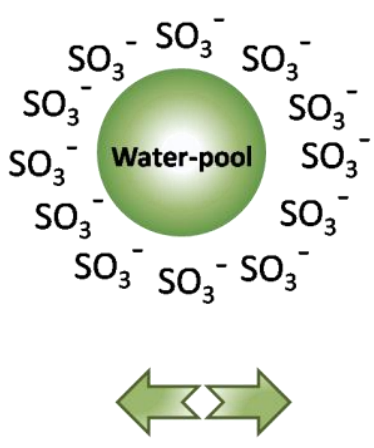

Proton gradient

(a)

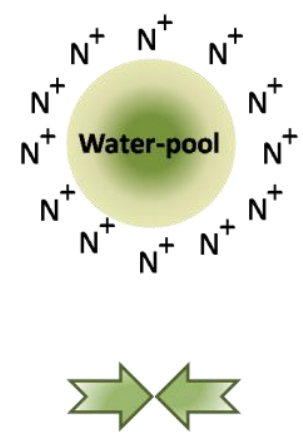

Proton gradient

(b)

Figure7. Proton gradient inside the water-pool of the reverse micelle of (a) anionic surfactant (e.g., AOT); (b) cationic surfactant (e.g., CTAB).

A concept proposed by some researchers [96], but not generally accepted [97], is the buffer-like action of water from RM due to the effect of titratable head groups of surfactant, the component with the higher concentration in the RM aggregates. This behavior it was reported especially for AOT surfactant which maintains the inside $\mathrm{pH}$ values to 5.0-5.5 for any value of the bulk buffer used, while the surfactant mixture $\mathrm{CTAB} /$ hexanol has a very low buffering capacity in the experimental range of $\mathrm{pH}$ from 4 to 10 [94].

All measurements of local $\mathrm{pH}$ in RMs are subject to the influence of a diversity of factors, as ionic strength, viscosity, polarity, conductivity etc, therefore a considerable attention must be paid to the accuracy description of $\mathrm{RM}$ components and experimental conditions, especially for comparative studies. Since 1992, Walde [98] has warned about the pH artifacts caused either by high concentrations, acidic/basic substrates or impurities or products in enzymology experiments.

\section{Biomimetic relevance of RMs}

A large variety of biological systems, e.g., lipid layers and protein pumps, and biochemical functions, e.g., macromolecular recognition and biocatalysis, takes place in nano-restricted environments delimited by cellular membranes inside cells and/or cellular organelles. Furthermore, intracellular environment is characterized by a compact, but highly compartmented structure and a 
heterogeneous matrix containing a large amount of various macromolecules with different shapes and sizes.

Conventionally biological/biochemical studies in vitro confers only a basic view [99] regarding intrinsic information of biomolecules structure and functions caused by the isolation through extraction procedures and removing of macromolecules from their natural matrix, accomplished by loss of structured microenvironment and partial alteration of the native structure and functions from in vivo environment. In addition, to avoid aggregation problems and to minimize the nonspecific interactions that occur at high concentrations, studies are generally performed in a diluted buffered solution, which is a too simple environment to the compositional complexity of the intracellular medium.

Addressing towards these major limitations regarding the relatively idealized thermodynamic conditions of "physiological conditions" used in vitro, so-called "synthetic cells" were proposed, representing simplified mimics of biological cell environment, including biomembranes, cytoplasmatic structure and inside interactions [100]. A successful approach to achieve the correlation of in vitro with in vivo conditions imply selection of an appropriate model that can simulate in a high degree the structure and functions of the biomolecules, in particular proteins, in biological membrane structures. Currently, the inverse micelles are recognized as biomimicking models with biological relevance for in vivo cells as well as structures like bilayers, liposomes and biomembranes [101-103].

An additional experimental advantage of RMs is represented by the optical transparency of the system even at millimolar concentrations of peptides, being available for spectroscopic analysis of water dynamics and active proteins conformation in cell mimics.

Basic principles which make RMs of great interest as biomimetic model are generally referring to (i) confinement and crowding cytoplamastic environment, (ii) molecular dynamics of water, (iii) biomembrane structure.

\subsection{Confinement and crowding}

Confinement concept is referring to the accessible volume within a "cage" in contrast with the dispersion throughout the space. Starting from the RMs definition as nano-pockets of water capped by a monolayer of surfactant, it is obvious that they are good candidates for confinement model of macromolecules included in restricted-volume [104, 105]. Even there are some common features as closed geometry and limited sizing to the range of macromolecules dimensions, certainly many other aspects differentiate RMs from biological environment, even if we are referring just to the simple interface composed only of a mono- or two constituent(s) that is radically different from the complex multi-components structure of biological walls/membranes [106].

In addition to the restricted volume, intracellular environment is characterized by high concentration of macromolecules which occupy the cellular volume in a range of 5-40\% [107]. All macromolecules from inside have different degrees of contribution to this high value, but none individual species are itself at high concentration. Therefore, cytoplasmatic space is generally considered a crowded environment, not a concentrated one [108,109]. Crowding phenomenon is a closely related concept to confinement, promoting non-specific interactions between neighboring molecules [110, 111].

Based on excluded volume principle, defined as the volume occupied by macromolecules and unavailable to other ones [112], it is considered that confinement has a main stability effect upon the proteins inside [113], while the crowding contribution is reduced. Instead the crowded space is involved in the exclusion of volumes (e.g. water) from the proximity of one molecule by the presence of the other macromolecules (e.g., proteins, polysaccharides, nucleic acids). It is assumed that basic mechanisms implied consist in: (i) reduction of entropic energy for protein folding cause by the limitation of possible protein conformations and entropy of unfolded state; (ii) modification of water properties due to the vicinity and implication of the interface composed of surfactant and macromolecules, as well of ions [114]. Anticipating to have interconnected effects, these two phenomena are considered to affect in different extents the essential reactions and events in a living 
cell as well as most of the protein features in cellular environments, from protein folding and stability, conformational behavior and protein dynamics to biological activity. It is worth mentioning their role in promoting proteins conformation of compact unfolded state and in favoring the dynamic process of transition from unfolded to folded state of protein, respectively the folding rate [115].

\subsection{Models for Molecular Dynamics of Water in Restricted-Volume}

The properties of pure water are generally related with the extended network of hydrogen bonds, while the water from natural/biological systems is significant different, mainly as a consequence of the truncated H-bonds network caused by confinement and expressed in the reduction of cooperative effects. The presence of interface which is in the most cases highly charged and the nanoscale-confinement imply the rearrangement of H-bonds network, resulting a structural dynamics of water molecules in bio-environment which is significant different from that in bulk water.

Reverse micelles are considered as convenient models for study structural organization and dynamics of water molecules in restricted-volume environment. Besides their appropriate structure with the natural model, they provide an approachable as well as tunable system for monitoring water dynamics and interfacial effects in such media [67].

Over the past decades, the dynamics of water molecules inside RM have been intensively explored, a wide range of experimental techniques being applied to measure either the responses of individual molecules of water from RM, or the evolution of the hydrogen-bonds network from inside the water-pool [103, 116-119]. The special steady-state spectra and population relaxation experiments are correlated with the energy level of the system, while spectral diffusion and orientational relaxation are generally governed by global H-bonds network structural evolution [120]. Numerous studies concerning water from the interior of RM revealed an inhomogeneity of water characteristics defined by a multilayered structure, putting into the question if water from RM can be approach as a single species or two or more separate populations [121-123].

The experimental observables provide by different methods do not always lead to the same model of structural organization and dynamics of water, the authors generally explaining the discrepancy through the characteristics and particular approaches of the measuring techniques. For instance, the absorption spectra and vibrational time decays discriminate various H-bonding environments in RMs while orientational and spectral diffusion functions suggest a size-dependent dynamic which is not strong influence by spatially location inside RMs.

Based on these different considerations, many research groups have suggested several models to formulate water inside the nanodroplets which became landmarks in the complex approach of water behavior in RM. The core-shell model $[117,124]$ considers that water properties are influenced only locally, dividing the nanoscopic water pool into two subensembles: the core, located in the center of droplet at some distance from the head groups and characterized by similar properties with bulk water, and the shell, bound to the surfactant layer, modeled by particular properties of water associated with the head groups of surfactant.

Applying this well-known model in their studies, Fayer [33, 105, 125] and Levinger [82] reported the results of experiments regarding water in RMs with different size (large, small, intermediate) concluding that large AOT RMs consist in two ensembles of water, while in small ones only a single water structure have been detected. They define the properties of water in shell layer as corresponding to the characteristics of $\mathrm{w}_{0}=2 \mathrm{RM}$, where all water molecules are interacting with the surfactant interface. According to their conclusions, water in RM with medium size (about $\mathrm{W}_{0}=10$ ) has an intermediate state between the collective dynamics (small RM) represented by coupled situation and two ensemble dynamics related to separation into components (large RM). In this case, the interface water has influence on the dynamics of water molecules situated at distance from the interface, while the dynamics of all molecules however did not correspond to one group as in small RMs. Even if the water dynamics in medium RM are separable into two components, their 
small size of water-pool does not allow the interface influence to entirely disappear and to form a water core similar to bulk water as in large RMs.

Bakker \& coworkers calculated the relative fraction of shell and core water in RM based on the anionic AOT or cationic CTAB and observed a size-dependent of orientational dynamics to the distance from the interface [126-128]. Based on these results, the authors considered that all water molecules encapsulated in RM, regardless of their spatial location inside the micellar pool, suffer modification of their vibrational relaxation rate according to the alteration of H-bond network. These nanoconfinement effects are the base for so-called "homogeneous droplet" model [128], which deal all water molecules as being identical throughout the micellar droplet due to the rapid transfer of intermolecular energy. According to Piletic, the water inside the small RM shows a more homogeneous dynamic through the water-pool due to a collective nature of $\mathrm{H}$-bond network [124].

The validity of core-shell model was experimental confirmed only for the cases when the properties of micellar water molecules do not imply the H-bond network. Instead, the measurements of orientational relaxation were in good agreement with investigations of the complex rotational motion of molecules in supramolecular systems performed with nanosecond fluorescence polarization technique. According to the "wobble-in-a-cone" model [129], the free rotation is restricted to an angular scale ranging within a cone caused by the orientational constraints imposed through the structural rearrangement of the $\mathrm{H}$-bonds from the surrounding framework. In the same time, the internal friction decreases the rate of reorientational motion inside organized structures compared to the expected value in an aqueous media [130]. The model defines a correlation between the time scales require for the orientation of water molecules in a restricted structure and for complete orientational relaxation during the randomization of the whole network of H-bonds. The randomization process assumes splitting of the existing H-bonds and forming of new ones in a similar way to Ivanov jump reorientation model [131] and extended jump model proposed by Laage [121]. Thus, in small RMs, it has been detected a separation of time scales because the limit of cone angular is achieve before the finalization of total randomization and that is associated with an observed biexponential decay of reorientation. In contrast, no separation in time scales (single-exponential decay) was noticed in large RMs where a reverse situation is encountering (first, the complete randomization, secondly reaching of limited cone angular).

Moilanen have identified two main factors that contribute to the transition from the bimodal nature of dynamics to a collective one: the mechanism of water reorientation and the nature of interface related to RM size [75]. The first is based on the model proposed by Laage and Hynes [121] which consider the water molecules reorientation as an unlocated process in which reorientation of one molecule cause the rearrangement of other about 16 molecules from the first and second shell of solvation and so affects their dynamics too. The most significant effect is observed in small RMs where the dynamics of most of molecules of water is slowing down even if they are at distance from the interface while this effect quickly disappears in the presence of a greater number of water molecules as in large RMs. The second factor is referring to the changing structure of the RM interface once with the reduction of RMs size, in particular with the characteristic of the curvature and surface area per head group. So, large RMs ( $w_{0} \geq 16.5$ ) have a gentle curvature of the interface showing an almost planar surface while the decreasing of RMs size from wo 16.5 to 6 is associated with a significant surface curvature and an increased rigidity of interface structure caused by simultaneously interactions of water molecules with multiple head groups.

In RMs have been identified two components of solvation dynamics, a fast one (subpicoseconds) and a slow one (ranging from hundreds to 1000 picoseconds) which is not encountered in bulk water. To understand this special behavior of water in confined geometries, the theoretical models have been used for molecular dynamic (MD) simulations as simplified singlesite or simple potential interaction models [67]. Even if not all interactions are taking into account, the MD simulation is considered to be a qualitatively model for solvation dynamics in restrictedsize environment. Among many suggestions, a special interest is represented by the MD simulation proposed by Senapathy and Chandra [132], which delimits the interactions contributions of the 
water from the interfacial layer of other effects (e.g. interactions between water and surfactant molecules). In their MD simulations, Faeder and Ladanyi examined the effects of RMs size, treating at molecular level only water and headgroups of surfactant, while the interior is modeling as a rigid spherical cavity and the surfactant tails and the apolar medium as a continuum. The simulations identified distinct water molecular layers indifferent of the size of RMs.

\subsection{Biomembrane structure}

For a long time, only the protective role of biomembranes was taken into account and their participation to others life process was minimized. More recently, it was reported the dynamic role of biomembranes, changing the concept of passive matrix in the case of biomolecular reactions [133, 134]. Beside proteins, a large contribution of lipids-bilayers has been identified in cellular activities as the mediation role in cellular metabolism or transmission of information [135]. In some cases, the influence of biomembranes in the evolution of cellular life has also been shown, inclusive in the malignization process where significant differences between normal and malign cells have been detected at this level [10, 133].

In living cells, transmembranal flow of various compounds (e.g., metabolites, nutrients etc) assumes the rearrangement of the amphiphilic phospholipids-bilayer. Different intermediate membranous structures with carrier role have been identified, including reverse micellar structures. The similarity with natural structures from living cells membranes confers unequivocally to the synthetic reverse micelles the status of a membrane-mimetic system.

Thus the well-known RMs consisting of AOT-isooctane-water were used for study the insertion of myelinic protein into cells biomembranes [136, 137]

With the reconsideration of biomembranes role, inclusive their mimics, RMs, have been no longer treated as just passive aggregates with interesting structures. A substantial argue in this regard is supported by the discovery of possible initiation of self-replication of RMs based on the reaction that occurs within micellar structures $[138,139]$.

The recognized status of RM as membrane mimetic was valorized in the investigation of different membranal processes as electron transfer [140], in the evolution of micellar structure or intermicellar interactions. In the last case, the structure of RM, in particular AOT-RM, is assimilated with a hard-sphere of repulsive forces (surfactant charged head groups) [141] operating with a tight attractive outer shell (surfactant tails). Interactions between RMs mainly experience the mechanism of collision-fusion-fission for the exchange of internal content [142]: first step imply the Brownian motion, the second one is characterized by attractive energy and adhesive interactions at micellar surface level in the absence of Coulombian rejection, while the third stage is the result of short-life of the instable dimer formed [143, 144].

Useful information regarding various processes in RM systems, forces and interactions between RMs, are based on the examination performed with simple and rapid electrochemical technique such as the steady-state microelectrode voltammetric investigation. Also a significant scientific contribution can provide the electroactive probes located at different redox active sites (e.g., aqueous core, internal or external micellar surface) in membrane mimetic structures [145].

Therefore, the importance of RMs as cell membrane-mimetic system is increasing being a convenient experimental approach to reproduce, even in part, such complex supramolecular organization in an artificial system [146]. Some researchers even propose RMs as model for the very first membranous structures, namely the primitive membranes that supported the self-replication cycles at the beginning of planet [10,147]. Due to their involvement in reactions that precede the process of life, in many opinions RM structures may be placed at the interface between "non-living" and "living" [138, 139].

\section{Nanomaterials Synthesis using RMs for development of nanosensors}

The large fields of nanotechnology and nano-based sensors have known an increasing interest in the last decades. The application of nanotechnology in (bio)sensors production led to an 
extensive range of applications, allowing miniaturization and enabling their integration in many other devices.

Development of nano-(bio)sensors is based on the use of the nanomaterials either as directly sensing elements or as associated materials to detect specific molecular interactions occurring at nano-scale.

Thus, chemical and physical methods have been the most used techniques for fabrication of the well-defined inorganic nanomaterials, moreover chemical vapor deposition, electrodeposition or metal-organic vapor deposition-based on ionic, atomic or molecular precursor decomposition represented viable routs for obtaining ordered nanoparticle networks [148]. Since the special properties of the nanomaterials, such as: mechanical, chemical, physical, optical, electrical, magnetic, thermal and biomedical are strongly dependent on the size, composition and shape of the nanostructures, different approaches have been taken into consideration for controlling the nanomaterial fabrication.

The high surface-to-volume ratio and the novel physico-chemical properties of the nanomaterials led to achievement of high performances in terms of sensitivity, selectivity and detection limits, so nano(bio)sensors have found application in various fields, including clinical diagnostic, environmental monitoring, food quality control and processing, pharmaceuticals, agricultures, through on site, in situ and on-line determinations [148].

Thus, in the last years, a considerable attention has been paid for designing and synthesis of the nanomaterials (nanoparticles, nanodots and nanotubes) with specific properties for advance applications by using organized self-assembled microemulsions [37]. Reverse micelles represent nanoscale hydrophilic cavities of microemulsions and environmentally friendly alternative used for the first time as nano-templates for nanomaterial synthesis, thus being obtained for the first time nanostructures of palladium, platinum and rhodium [37].

Different approaches for nanoparticles synthesis through RMs have been reported in literature, using different materials, such as metals [149-151], metal-oxides [152 - 154], nanocomposites [155], and supported catalysts [156, 157].

Microemulsions represent thermodynamically stable dispersions of amphiphilic surfactants, the reverse micelles microemulsions being formed when water is dispersed in hydrocarbon based continuous phases. Thus, a hydrophilic head groups region is resulting, surrounding a nanometersized water core with hydrophobic tails extending in the continuous phase [101]. These systems are dynamic, being described as nanoreactors, micelles collide due to the Brownian movement and coalesce to form dimers, which exchange contents when break apart again, a process which usually occurs very fast (less than $1 \mathrm{msec}$ ) [158, 159]. This process is very important for the nanoparticles synthesis, micelles in these systems providing the appropriate environment for nucleation and growth control, the last stage being the stabilization of the system by addition of surfactant, thus preventing the aggregation of nanoparticles [158]. Also, the modification and control of the RM structures can be achieved by addition of a cosurfactant [160].

Among different surfactants used in formulating microemulsions for nanoparticle synthesis, the anionic double-chained sodium bis(2-ethylhexyl) sulfosuccinate (AOT) and nonionic polyoxylethyl-5-nonylphenyl ether are the most used surfactants, due to their ability to form thermodynamically stable reverse micelles and microemulsions, through solubilization of high amounts of water in different hydrophobic organic solvents and without the need of other cosurfactants [161].

The recovery of the nanoparticles from the reverse micelles representing one of the key step, the most common used methods being flocculation [162], evaporation to dryness [163] or addition of certain chemical reagents [164] which undergo the phase separation and simultaneous precipitation of the surfactant.

Different nano(bio)sensors have been developed based on nanoparticles, nanotubes or quantum dots obtained by reverse micelle method, for sensitive detection of sugar, amino acids, hydrogen peroxide, hydrogen, nitric oxide, phenolic compounds or biotin-streptavidin, the advantages occurring in lowering the overpotentials of many electrochemical reactions, turning 
into reversible redox reactions that are normally irreversible in conventional unmodified electrodes and enhancing the electron transfer between biomolecules .

Thus, Ferreira et al reported an electrochemical sensor based on rhodium nanoparticles for determination of some phenolic compounds in cellulose matrix [165]. Rhodium nanoparticles obtained by reduction of rhodium ions entrapped in reverse micelles, and stabilized in 3-(1tetradecyl-3-imidazolium) propanesulfonate surfactant were used for coating the surface of a glassy carbon electrode [165]. These metallic nanoparticles stabilized with the zwitterionic surfactant were found to lower the electron transfer resistance at the electrode surfaces by enhancing the electrical conductivity at the electrode surface. By using this sensor, the authors reported the determination of p-coumaric acid in a cellulose matrix, with good reproducibility and reproducibility, at a detection limit of $0.6 \mu \mathrm{mol} \cdot \mathrm{L}^{-1}[165]$.

Palladium and gold nanoparticles prepared by RMs method and stabilized by using the same surfactant were used in development of electrochemical sensors for hydroquinone and catechol determination [166,167]. Zapp et al have reported the modification of a glassy carbon electrode with a bio-complex based on palladium nanoparticles stabilized with zwitterionic surfactant for simultaneous electrochemical determination of catechol and hydroquinone in cigarrete residue samples [166].

A biosensor for determination of hydroquinone has been developed by Fernandes et al, by immobilization of peroxidase onto gold electrodes, using a solution of well dispersed gold nanoparticles stabilized with zwitterionic surfactant [167]. The developed biosensor was used for electrochemical determination of hydroquinone in skin-brightening creams, at a low applied potential of $0.09 \mathrm{~V} \mathrm{vs} \mathrm{Ag} / \mathrm{AgCl}$, with a detection limit of $0.188 \mu \mathrm{mol} \cdot \mathrm{L}^{-1}$ [167].

A nanocomposite based on PdO-loaded on $\mathrm{SnO}_{2}$ nanoparticles was prepared by Yuasa and coauthors, by precipitating $\mathrm{Pd}(\mathrm{OH})_{2}$ and $\mathrm{Sn}(\mathrm{OH})_{4}$ inside a $\mathrm{RM}$, followed by calcination [168]. The obtained nanocomposite was used further to design a thick film sensor device by screen-printing method for $\mathrm{CO}$ gas sensing. Tin oxide $\left(\mathrm{SnO}_{2}\right)$ represents an attractive material for designing semiconductor gas sensors because of its physico-chemical properties, high sensitivity and chemical stability. The authors showed that the electrical resistance and the response of the designed sensor is highly dependent on dispersion state of $\mathrm{PdO}$ onto $\mathrm{SnO}_{2}$ [168]. By loading $\mathrm{PdO}$ on $\mathrm{SnO}_{2}$, the electric resistance increased, because $\mathrm{PdO}$ acted as a stronger acceptor of electrons and removed electrons from the oxide, but when PdO is reduced to Pd by contact with reducing gases, the electric resistance decreased by back electron transfer from $\mathrm{Pd}$ to $\mathrm{SnO}_{2}$. Usually, the big difference in the electrical resistance of $\mathrm{SnO}_{2}$, due to the oxidized/reduced states of Pd leads to a high increase in response to the reducing gases $[169,170]$.

An oxygen reduction based electrode has been designed by modification with carbonsupported $\mathrm{LaMnO}_{3}$ nanoparticles by Yuasa et al [171]. The nanoparticles of $\mathrm{LaMnO}_{3}$ were easily prepared by reduction-oxidation reaction between $\mathrm{Mn}\left(\mathrm{NO}_{3}\right)_{2}$ and $\mathrm{KMnO}_{4}$ precursors in $\mathrm{RMs}$ [171, 172]. The black carbon dispersed in cyclohexane was added into the reverse micelle solutions containing the precursors, while the ethanol was used to break the micelles and to directly precipitate the carbon-supported $\mathrm{LaMnO}_{3}$ precursors. The gas-diffusion-type electrode prepared by modification with $\mathrm{LaMnO}_{3}$ nanoparticles showed high oxygen reduction activity [172].

Nanoparticles of palladium and platinum represent the two most preferred catalytic metals with a high capacity of absorbing hydrogen, improving considerable the sensitivity of hydrogen detection [173, 174]. Thus, Grym et al have reported the development of a hydrogen sensor based on semiconductor Schottky barriers and electrophoretic deposition of palladium nanoparticles obtained by RM method onto InP substrates [175]. Colloidal solutions of spherical palladium nanoparticles with diameters of 7 to $10 \mathrm{~nm}$, dispersed in isooctane, have been prepared by mixing two reverse micelle solutions, with the same molar ratio of $\mathrm{H}_{2} \mathrm{O}$ to AOT, one containing $\operatorname{Pd}\left(\mathrm{NH}_{3}\right)_{4} \mathrm{Cl}_{2}$, while the second one contained hydrazine as reducing agent. Electrophoretic deposition of the obtained palladium nanoparticles has been achieved in a cell with two electrodes, by applying an electric field of $2000 \mathrm{~V} / \mathrm{cm}$, for about $50 \mathrm{~ms}$ [175]. One of the electrode was fabricated from pure-graphite, while the other electrode was prepared by an epi-ready InP substrate, the 
distance between electrodes being maintained at $1.5 \mathrm{~mm}$. The detection limits obtained with these diodes for hydrogen was about 1 ppm $\mathrm{H}_{2} / \mathrm{N}_{2}[175,176]$.

Copper sulfate was used by Davarpanah et al, as precursor for obtaining $\mathrm{CuO}$ nanoparticles in RMs, using Tween 80 as surfactant [177]. The gas sensing properties of as-obtained $\mathrm{CuO}$ nanoparticles were further investigated by authors, by designing sensors for detection of $\mathrm{NO}_{2}$ and alcohols. The NO2 detection was performed with low energy consumption and operation temperature [177].

Optical sensing devices have been developed based on thin films of CdS nanoparticles obtained by RM technique [178]. The authors succeeded to immobilize into films the CdS nanoparticles synthetized in RM solution by using AOT as stabilizer, onto solid surfaces (Si wafers), avoiding the modification of the nanoparticles properties as sensing medium. The obtained nanoparticles were cast into films and immobilized onto solid surfaces using porous polymeric and sol-gel matrices, further being exposed to several organic compounds (hydrocarbon compounds). Since these nanoparticles showed a relatively bright photoemission, the designed sensor was used to identify the target compounds and their specific concentrations based on photoluminescence detection [178].

Development of uniform magnetic nanoparticles represents an important issue in designing ultrahigh-density magnetic sensors. The most used magnetic oxides materials in the development of magnetic nanoparticles based sensors are magnetite $\left(\mathrm{Fe}_{3} \mathrm{O}_{4}\right)$, cobalt ferrite, nickel ferrite and zinc ferrite $\left(\mathrm{MFe}_{2} \mathrm{O}_{4}\right.$ - where $\mathrm{M}$ is a metal such as $\left.\mathrm{Co}, \mathrm{Ni}, \mathrm{Zn}\right)$, being well known that the magnetic hardness of these materials is defined by anisotropy of nanoparticles within an exchange length [179]. There are different approaches reported in literature for synthesis of magnetic nanoparticles for sensors development, including thermal [180] and sonochemical [181] decomposition of organometallic precursors, high temperature reduction of metal salts [182] and reduction inside of RMs [183].

Wiedwald et al have reported the preparation of monoatomic ( $\mathrm{Fe}, \mathrm{Co}$ ) and bimetallic (FePt and CoPt) nanoparticles with diameters of 2 to $12 \mathrm{~nm}$, by loading precursors in RMs [184]. The authors have used polystyrene-block-poly(2-vinylpyridine) and polystyrene-block-poly(4-vinylpyridine) in anhydrous toluene to form reverse spherical micelles. The pyridine groups of the micelle core allowed the selective loading of the precursors, $\mathrm{FeCl}_{3}$ and $\mathrm{CoCl}_{2}$ [184]. In the case of the bimetallic nanoparticles, the platinum precursors $\left(\mathrm{H}_{2} \mathrm{PtCl}_{6}, \mathrm{PtCl}_{4}\right.$ and $\left.\mathrm{K}\left[\mathrm{PtCl}_{3} \mathrm{C}_{2} \mathrm{H}_{4}\right] \cdot \mathrm{H}_{2} \mathrm{O}\right)$ were added first to the micelle solution, stirred until loading was completed and followed by addition of the $\mathrm{FeCl}_{3}$ or $\mathrm{CoCl}_{2}$.The deposition of the loaded reverse micelles onto different support was accomplished by immersing the substrates into the micelle solution and extracted out under ambient condition with a constant controlled rate [184].

Conducting polymers nanostructures (nanofibers, nanowires and nanotubes) are also very studied for versatile sensors development, due to properties, such as reversible signal transduction mechanism, tunable sensitivity and design flexibility in sensors applications [185-187]. Polypyrrole and polyaniline nanotubes have been fabricated inside of the cylindrical pores of the templates [188-190].

Ellipsoidal nanoparticles, nanorods and nanotubes of poly(3,4-ethylenedioxythiophene) (PEDOT) have been fabricated by Yoon et al, based on chemical oxidation polymerization in RMs [191]. The AOT surfactant and aqueous solution of $\mathrm{FeCl}_{3}$ in hexane were used for preparation of reverse cylindrical micelles. The obtained PEDOT nanostructures were immobilized onto a microelectrode substrate through a casting solution, the nanotubes forming networks which provided excellent performance for the developed sensor. The chemical sensors based on PEDOT nanotubes were applied for detection of alcohol vapors, their responses being reproducible and reversible [191].

Quantum dots (QD), known as semiconductor nanoparticles, with dimensions ranging from 2 to $20 \mathrm{~nm}$, represents crystalline clusters having great potentials of applications as fluorescent labels for molecular, cellular and in vivo imaging determinations. QDs are more stable and cheaper compared to existing labels (fluorescent dyes) [192], and due to their special optical and 
electrochemical properties (such as narrow and size-tunable emission spectra, high stability, excellent resistance to chemical degradation and broad absorption spectra) [193,194], QDs allow more flexible, faster binding kinetics, high sensitivity and high reaction rates for many types of analysis, from immunoassays to DNA assays [195]. The QDs can be prepared from different materials, such as metals (Gold, silver or cobalt) [196,197], semiconductors (CdS, CdSe, InP) [198,199] and insulators $\left(\mathrm{Fe}_{3} \mathrm{O}_{4}, \mathrm{SnO}_{2}\right)$ [200,201], through organometallic thermolysis [198], electrochemical deposition [202] and colloidal self-assembled pattern formation by surfactant micellation [203]. Using different QDs and electrochemical detection methods, multiple analysis can be performed, from applications in gene expression, high-speed screening and medical diagnostics, to environmental and food analysis [195].

Thus, Merkoci et al have used QDs based on cadmium, lead and zinc suphide nanoparticles for electroanalytical applications. The quantum dots were obtained by RMs method, adding cadmium, lead or zinc nitrate and sodium sulphide to an AOT/n-heptane water-in-oil microemulsion [204]. The conjugates of $\mathrm{CdS}, \mathrm{PbS}$ and $\mathrm{ZnS}$ with DNA have been prepared, by using aqueous solutions of each nanoparticle and thiolated oligonucleotide samples, and further, the detection of DNA was achieved by authors using streptavidin-coated magnetic beads and CdS QDs [204].

In order to increase the colloidal stability of QDs and to decrease the non-specific adsorption different strategies have been reported based on encapsulation of QDs into micelles or other particles. Thus, Dubertret et al have encapsulated fluorescent semiconductor nanocrystals into lipid micelles, comprising n-poly(ethyleneglycol) phosphatidylethanolamine and posphatidylcholine, the advantage of these micelles consisting in their very regular size, shape and structure [205]. Electrochemical applications were developed based on encapsulation of QDs, such as CdS, ZnS and $\mathrm{PbS}$ nanoparticles, within polystyrene beads, in order to create an electrochemical codes library [206]. Wang et al have developed encoded redox beads for electrochemical identification, based on encapsulation of different QDs into polystyrene microspheres [206]. The obtained redox-encoded nanoparticles were used further as label sensors, for a large number of recognizable voltammetric signatures in cover tagging of commercial products [206].

In conclusion, the versatility of RMs technique allowed the preparation of different nanomaterials by using water-in-oil microemulsions, and further designing sensitive and selective nano-(bio)sensors with large scale of applications.

\section{Conclusions}

This review presents a basic view on the fundamental characteristic of RMs, from their relationship with the molecular bases of microemulsion formation to the main particular features of RMs which distinguished them from other microemulsions and confers a distinct identity in this large family.

A special attention has been paid to define both the $\mathrm{pH}$ concept across the water-pool of RMs and the experimental significance of water-pool $\mathrm{pH}$ in order to underline the need of a correct methodology for preparing/adjustment of the $\mathrm{pH}$ from water-pool to a said $\mathrm{pH}$ value that is appropriate to a particular application (e.g., special requirements for active conformation of biomolecules or nano-particles synthesis). The structural and compositional flexibility of RMs supports their significance in a surprising large range of functional areas and versatile approaches of RMs: from theoretical model to practical applications.

From the available information regarding the biomimetic relevance of RMs as an appropriate and accessible model of cellular structure, the review is focusing on three aspects seen in our opinion as the most interesting and captivating: confinement and crowding cytoplamastic environment, dynamics water in restricted-volume and the dynamic role of membraneous structures.

On the other hand, the review is directed to the applied contribution of the RMs to the development of nanotechnologies for synthesis of nano-materials for nano-devices design, with a special reference to nano(bio)-sensors. A large variety of nanomaterials with uniform size have been prepared by using RMs as nanoreactors. The nanosized aqueous cores of the reverse micelles 
provide an appropriate stable environment for nanomaterials synthesis. The aggregation of the nanomaterials dispersed in RMs is inhibited by the surfactant layers, which act as stabilizers. The main advantage of using RMs in nanoparticles synthesis consists in the fact that is a simple technique, operating at room-temperature and pressure and it does not require special equipment. Moreover, RMs method allows the obtaining of a large number of nanoparticles with a good control of the size and morphology of the particles formed, even in homogenous solution.

Author Contributions: M.-L.A. and M.D. conceived the structure of the paper; M.-L. A.-M.G. and L.-M.J. collected the references; M.-L.A., A.-M.G. and L.-M.J. wrote the paper; M.-L.A., A.-M.G., M.-L.J. and M.D. revised the paper.

Funding: This work was supported by a grant of the Romanian National Authority for Scientific Research and Innovation, CCCDI - UEFISCDI, project number ERANET-MANUNET II -TOX-HAZ-ASSESS no 33/2017 within PNCDI III.

Acknowledgments: The authors thanks to Ministry of Research and Innovation through Program 1Development of the National Research \& Development System, Subprogram 1.2 - Institutional performance Projects of Excellence Financing in RDI, project number PFE no 31/2018

Conflicts of Interest: The authors declare no conflict of interest.

\section{References}

1. Tan, H.-S.; Piletic, I.R.; Fayer, M.D. Orientational dynamics of water confined on a nanometer length scale in reverse micelles. The Journal of Chemical Physics 2005, 122, 174501, doi:10.1063/1.1883605.

2. Yeung, P.S.W.; Eskici, G.; Axelsen, P.H. Infrared spectroscopy of proteins in reverse micelles. Biochimica et Biophysica Acta (BBA) - Biomembranes 2013, 1828, 2314-2318, doi:https://doi.org/10.1016/j.bbamem.2012.10.019.

3. Martinek, K.; Levashov, A.V.; Klyachko, N.; Khmelnitski, Y.L.; Berezin, I.V. Micellar enzymology. European Journal of Biochemistry 1986, 155, 453-468, doi:10.1111/j.1432-1033.1986.tb09512.x.

4. van der Loop, T.; Panman, M.; Lotze, S.; Zhang, J.; Vad, T.; Bakker, H.; F C Sager, W.; Woutersen, S. Structure and dynamics of water in nonionic reverse micelles: A combined time-resolved infrared and small angle $x$ ray scattering study; 2012; Vol. 137, pp. 044503.

5. Luisi, P.L.; Giomini, M.; Pileni, M.P.; Robinson, B.H. Reverse micelles as hosts for proteins and small molecules. Biochimica et Biophysica Acta (BBA) - Reviews on Biomembranes 1988, 947, 209-246, doi:https://doi.org/10.1016/0304-4157(88)90025-1.

6. Singh, K.; Iqubal, M.K.; Shukla, V.K.; Shuaib, M. Review Article Microemulsions: Current Trends in Novel Drug Delivery Systems; 2014; Vol. 1, pp. 39-5139.

7. Kabanov, A.V.; Levashov, A.V.; Klyachko, N.L.; Namyotkin, S.N.; Pshezhetsky, A.V.; Martinek, K. Enzymes entrapped in reversed micelles of surfactants in organic solvents: A theoretical treatment of the catalytic activity regulation. Journal of Theoretical Biology 1988, 133, 327-343, doi:https://doi.org/10.1016/S0022-5193(88)80325-4.

8. McClements, D.J. Nanoemulsions versus microemulsions: terminology, differences, and similarities. 2012, 8, 1719-1729, doi:10.1039/c2sm06903b.

9. Danielsson, I.; Lindman, B. The definition of microemulsion. Colloids and Surfaces 1981, 3, 391-392, doi:10.1016/0166-6622(81)80064-9.

10. UskokoviĆ, V.U.K.; Drofenik, M. SYNTHESIS OF MATERIALS WITHIN REVERSE MICELLES. Surface Review and Letters 2005, 12, 239-277, doi:10.1142/S0218625X05007001.

11. Langevin, D. Micelles and Microemulsions. Annual Review of Physical Chemistry 1992, 43, 341-369, doi:10.1146/annurev.pc.43.100192.002013.

12. Schulman, J.H.; Stoeckenius, W.; Prince, L.M. Mechanism of Formation and Structure of Micro Emulsions by Electron Microscopy. The Journal of Physical Chemistry 1959, 63, 1677-1680, doi:10.1021/j150580a027.

13. Sjöblom, J.; Lindberg, R.; Friberg, S.E. Microemulsions - phase equilibria characterization, structures, applications and chemical reactions. Advances in Colloid and Interface Science 1996, 65, 125-287, doi:https://doi.org/10.1016/0001-8686(96)00293-X. 
14. Narang, A.S.; Delmarre, D.; Gao, D. Stable drug encapsulation in micelles and microemulsions. International Journal of Pharmaceutics 2007, 345, 9-25, doi:https://doi.org/10.1016/j.ijpharm.2007.08.057.

15. A. Tovstun, S.; Razumov, V. What makes AOT reverse micelles spherical? Colloid Polym Sci 2015 ; Vol. 293, pp. 165-176, https://doi.org/10.1007/s00396-014-3405-7.

16. Sarvesh Katiyar, B.; Katiyar, S.; Satishchandra Mishra, P.; Lakshmi Sailaja, D. Microemulsions: A novel drug carrier system, Int. J. Pharm. Sci. Rev. Res. 2013; Vol. 20, pp. 138-148, ISSN 0976 -044X.

17. Thiam, A.R.; Farese, R.V., Jr.; Walther, T.C. The biophysics and cell biology of lipid droplets. Nature reviews. Molecular cell biology 2013, 14, 775-786, doi:10.1038/nrm3699.

18. Krishna, S.H.; Srinivas Nd Fau - Raghavarao, K.S.M.S.; Raghavarao Ks Fau - Karanth, N.G.; Karanth, N.G. Reverse micellar extraction for downstream processing of proteins/enzymes. Bioprocessing and Biotransformation. Advances in Biochemical Engineering/Biotechnology 2002, 75, pp 119-183 https://doi.org/10.1007/3-540-44604-4_5

19. Lawrence, M.J.; Rees, G.D. Microemulsion-based media as novel drug delivery systems. Advanced Drug Delivery Reviews 2000, 45, 89-121, doi:https://doi.org/10.1016/S0169-409X(00)00103-4.

20. Gillberg, G.; Lehtinen, H.; Friberg, S. NMR and IR investigation of the conditions determining the stability of microemulsions. Journal of Colloid and Interface Science 1970, 33, 40-53, doi:https://doi.org/10.1016/0021-9797(70)90070-6.

21. Moulik, S.; Paul, B. Structure, dynamics and transport properties of microemulsions. Advances in Colloid and Interface Science 1998; Vol. 78, pp. 99-195, https://doi.org/10.1016/S0001-8686(98)00063-3.

22. Moulik, S.; Paul, B. Uses and applications of microemulsions Current Science; 2001; Vol. 80, pp 990-1001, https://www.jstor.org/stable/24105809.

23. Chaurasiya, R.; Hebbar, U. Reverse Micelles for Nanoparticle Synthesis and Biomolecule Separation. Nanoscience in Food and Agriculture 4 2017; 24, pp. 181-211, https://doi.org/10.1007/978-3-319-53112-0_5.

24. Kilikian B. V., Bastazin M.R., Minami N. M., Gonçalves E. M. R., Junior A. P.. Liquid-liquid extraction by reversed micelles in biotechnological processes. Brazilian Journal of Chemical Engineering 2000, 17, pp 9 http://dx.doi.org/10.1590/S0104-66322000000100003.

25. Surabhi, K.; Katare, O.P.; Atul, N.; Arun, G. Microemulsions: Developmental aspects Research Journal of Pharmaceutical, Biological and Chemical Sciences 2010; Vol. 1, pp. 683-706, ISSN: 0975-8585.

26. Israelachvili, J. The science and applications of emulsions - an overview. Colloids and Surfaces A: Physicochemical and Engineering Aspects 1994, 91, 1-8, doi:https://doi.org/10.1016/0927-7757(94)02743-9.

27. Nagarajan, R. Molecular Packing Parameter and Surfactant Self-Assembly: The Neglected Role of the Surfactant Tail. Langmuir 2002, 18, 31-38, doi:10.1021/la010831y.

28. Ballesteros-Gomez, A.; Sicilia, M.D.; Rubio, S. Supramolecular solvents in the extraction of organic compounds. A review. Analytica Chimica Acta 2010, 677, 108-130, doi:10.1016/j.aca.2010.07.027.

29. Manaargadoo-Catin, M.; Ali-Cherif, A.; Pougnas, J.L.; Perrin, C. Hemolysis by surfactants - A review. Advances in Colloid and Interface Science 2016, 228, 1-16, doi:10.1016/j.cis.2015.10.011.

30. Durand, G.; Abla, M.; Ebel, C.; Breyton, C. New Amphiphiles to Handle Membrane Proteins: “Ménage à Trois" Between Chemistry, Physical Chemistry, and Biochemistry. In Membrane Proteins Production for Structural Analysis, Mus-Veteau, I., Ed. Springer New York: New York, NY, 2014; pp. 205-251, https://doi.org/10.1007/978-1-4939-0662-8_8.

31. Liu, Y.; Dong, X.; Sun, Y. New Development of Reverse Micelles and Applications in Protein Separation and Refolding. Chinese Journal of Chemical Engineering 2008, 16, 949-955, doi:https://doi.org/10.1016/S10049541(09)60022-7.

32. Maitra, A.N.; Eicke, H.F. Effect of rotational isomerism on the water-solubilizing properties of Aerosol OT as studied by hydrogen-1 NMR spectroscopy. The Journal of Physical Chemistry 1981, 85, 2687-2691, doi:10.1021/j150618a024.

33. Fayer, M.D.; Levinger, N.E. Analysis of Water in Confined Geometries and at Interfaces. Annual Review of Analytical Chemistry 2010, 3, 89-107, doi:10.1146/annurev-anchem-070109-103410.

34. Nave, S.; Eastoe, J.; Penfold, J. What Is So Special about Aerosol-OT? 1. Aqueous Systems. Langmuir 2000, 16, 8733-8740, doi:10.1021/la000341q.

35. Basheer, S.A.; Thenmozhi, M. Reverse micellar separation of lipases: A critical review. Int. J. Chem. Sci. 2010; Vol. 8, pp. S57-S67, ISSN 0972-768X. 
36. Fragoso, A.; Pacheco, R.; Karmali, A. Investigation of structural effects and behaviour of Pseudomonas aeruginosa amidase encapsulated in reversed micelles. Process Biochemistry 2012, 47, 264-272, doi:https://doi.org/10.1016/j.procbio.2011.11.001.

37. Eastoe, J.; Hollamby, M.J.; Hudson, L. Recent advances in nanoparticle synthesis with reversed micelles. Adv Colloid Interface Sci 2006, 128-130, 5-15, doi:10.1016/j.cis.2006.11.009.

38. Shrestha, L.K.; Dulle, M.; Glatter, O.; Aramaki, K. Structure of Polyglycerol Oleic Acid Ester Nonionic Surfactant Reverse Micelles in Decane: Growth Control by Headgroup Size. Langmuir 2010, 26, 7015-7024, doi:10.1021/la904231t.

39. Chuo, S.C.; Mohd-Setapar, S.H.; Mohamad-Aziz, S.N.; Starov, V.M. A new method of extraction of amoxicillin using mixed reverse micelles. Colloids and Surfaces A: Physicochemical and Engineering Aspects 2014, 460, 137-144, doi:https://doi.org/10.1016/j.colsurfa.2014.03.107.

40. Mitra, R.K.; Sinha, S.S.; Verma, P.K.; Pal, S.K. Modulation of Dynamics and Reactivity of Water in Reverse Micelles of Mixed Surfactants. The Journal of Physical Chemistry B 2008, 112, 12946-12953, doi:10.1021/jp803585q.

41. Bhowal S1, P.B., Rastogi NK. Mixed reverse micelles facilitated downstream processing of lipase involving water-oil-water (WOW) liquid emulsion membrane. Biotechnol Prog. 2014, 30, 1084-1092, doi:doi: 10.1002/btpr.1941.

42. Chakrabarty, D.; Hazra, P.; Chakraborty, A.; Sarkar, N. Solvation Dynamics of Coumarin 480 in Bile Salt-Cetyltrimethylammonium Bromide (CTAB) and Bile Salt-Tween 80 Mixed Micelles. The Journal of Physical Chemistry B 2003, 107, 13643-13648, doi:10.1021/jp0360467.

43. Mohd-Setapar, S.H.; Mohamad-Aziz, S.N.; Harun, N.H.; Mohd-Azizi, C.Y. Review on the Extraction of Biomolecules by Biosurfactant Reverse Micelles. APCBEE Procedia 2012, 3, 78-83, doi:https://doi.org/10.1016/j.apcbee.2012.06.050.

44. Rodrigues, L.R. Microbial surfactants: Fundamentals and applicability in the formulation of nano-sized drug delivery vectors. Journal of Colloid and Interface Science 2015, 449, 304-316, doi:https://doi.org/10.1016/j.jcis.2015.01.022.

45. Usman, M.; Dadrasnia, A.; Kang, T.; Mahmud, A.; Ismail, S. Application of biosurfactants in environmental biotechnology; remediation of oil and heavy metal. AIMS Bioengineering 2016; Vol. 3, pp. 289-304, doi: 10.3934/bioeng.2016.3.289.

46. Dong, X.-Y.; Meng, Y.; Feng, X.-D.; Sun, Y. A metal-chelate affinity reverse micellar system for protein extraction. Biotechnology Progress 2009, 26, 150-158, doi:10.1002/btpr.291.

47. Paradkar, V.M.; Dordick, J.S. Affinity-based reverse micellar extraction and separation (ARMES): A facile technique for the purification of peroxidase from soybean hulls. Biotechnology Progress 1993, 9, 199-203, doi:10.1021/bp00020a013.

48. Liu, Y.; Xiao, Y.; Sun, Y. Characterization of reversed micelles of Cibacron Blue F-3GA modified Span 85 for protein solubilization, J Colloid Interface Sci.; 2005; Vol. 290, pp. 259-266, doi:https://doi.org/10.1016/j.jcis.2005.04.017.

49. Goto, M., Kuroki, M., Ono, T., \& Nakashio, F. Protein extraction by new reversed micelles with di(tridecyl) phosphoric acid. Separation Science and Technology 1995, 30, 89-99, doi:https://doi.org/10.1080/01496399508012215.

50. Mathew, D.S.; Juang, R.-S. Role of alcohols in the formation of inverse microemulsions and back extraction of proteins/enzymes in a reverse micellar system. Separation and Purification Technology 2007, 53, 199-215, doi:https://doi.org/10.1016/j.seppur.2006.10.001.

51. Kadam, K.L. Reverse micelles as a bioseparation tool. Enzyme and Microbial Technology 1986, 8, 266-273, doi:https://doi.org/10.1016/0141-0229(86)90020-7.

52. Munshi, N.; Sarcar, S.; Maitra, A. The effect of droplet dynamics on the kinetics of the horseradish peroxidase catalysed reaction in reverse micelles, Colloids and Surfaces A: Physicochemical and Engineering Aspect; 1994; Vol. 88, pp. 181-189, doi:https://doi.org/10.1016/0927-7757(94)02778-1.

53. Fletcher, P.D.I.; Howe, A.M.; Robinson, B.H. The kinetics of solubilisate exchange between water droplets of a water-in-oil microemulsion. Journal of the Chemical Society, Faraday Transactions 1: Physical Chemistry in Condensed Phases 1987, 83, 985-1006, doi:10.1039/F19878300985.

54. Lindman, B.; Stilbs, P.; Moseley, M.E. Fourier transform nmr self-diffusion and microemulsion structure. Journal of Colloid and Interface Science 1981, 83, 569-582, doi:https://doi.org/10.1016/0021-9797(81)90351-9. 
55. Pomata, M.H.H.; Laria, D.; Skaf, M.S.; Elola, M.D. Molecular dynamics simulations of AOTwater/formamide reverse micelles: Structural and dynamical properties. The Journal of Chemical Physics 2008, 129, 244503, doi:10.1063/1.3042275.

56. Bru, R.; Sánchez-Ferrer, A.; García-Carmona, F. Kinetic models in reverse micelles. The Biochemical journal 1995, 310 ( Pt 3), 721-739, doi:10.1042/bj3100721.

57. Cringus, D.; Bakulin, A.; Lindner, J.; Vöhringer, P.; S Pshenichnikov, M.; Wiersma, D. Ultrafast Energy Transfer in Water-AOT Reverse Micelles J. Phys. Chem. B; 2007; Vol. 111, pp. 14193-14207, doi: 10.1021/jp0723158.

58. Kinugasa, T.; Kondo, A.; Nishimura, S.; Miyauchi, Y.; Nishii, Y.; Watanabe, K.; Takeuchi, H. Estimation for size of reverse micelles formed by AOT and SDEHP based on viscosity measurement. Colloids and Surfaces A: Physicochemical and Engineering Aspects 2002, 204, 193-199, doi:https://doi.org/10.1016/S09277757(01)01132-3.

59. Ricka, J.; Borkovec, M.; Uj, H. Coated droplet model of microemulsions: Optical matching and polydispersity J. Chem. Phys.; 1991; Vol. 94, pp. 8503-8509, doi:https://doi.org/10.1063/1.460083.

60. Lemyre, J.-L.; Ritcey, A. Characterization of a Reverse Micellar System by H-1 NMR Langmuir; $2010 ;$ Vol. 26, pp. 6250-6255, doi:https://doi.org/10.1021/la904033e.

61. Zinsli P. E., Inhomogeneous interior of Aerosol OT microemulsions probed by fluorescence and polarization decay J. Phys. Chem.; 1979; Vol. 83, pp 3223-3231, doi:https://doi.org/10.1021/j100488a008.

62. Kondo, H.; Fujiki, K.; Sunamoto, J. Reversed micellar catalysis. Catalysis of dodecylammonium propionate reversed micelles in the hydrolysis of alkyl p-nitrophenyl carbonates J. Org. Chem.; 1978; Vol. 43, pp 3584-3588, doi:https://doi.org/10.1021/jo00412a036.

63. Gębicki, J.L. Intermicellar material exchange in reverse micelles formed by ionic AOT and nonionic Igepal surfactants studied by means of pulse radiolysis. Influence of the temperature. Central European Journal of Chemistry 2004, 2, 371-387, doi:10.2478/BF02475580.

64. Chhaya, U., Ingale, S. Micellar Enzymology- Chemistry and Applications The Open Biotechnology Journal; 2016; Vol. 10, pp. 326-334, doi: 10.2174/1874070701610010326.

65. Menger, F.M.; Donohue, J.A.; Williams, R.F. Catalysis in water pools. Journal of the American Chemical Society 1973, 95, 286-288, doi:10.1021/ja00782a075.

66. Menger, F.M.; Saito, G. Adsorption, displacement, and ionization in water pools. Journal of the American Chemical Society 1978, 100, 4376-4379, doi:10.1021/ja00482a010.

67. Venables, D.S.; Huang, K.; Schmuttenmaer, C.A. Effect of Reverse Micelle Size on the Librational Band of Confined Water and Methanol. The Journal of Physical Chemistry B 2001, 105, 9132-9138, doi:10.1021/jp0112065.

68. Onori, G.; D'Angelo, M.; Santucci, A. Structure and state of water in reversed aerosol OT micelles: an infrared study Trends in Colloid and Interface Science VIII. Progress in Colloid \& Polymer Science. Steinkopff; 2007; vol 97 pp. 158-162, https://doi.org/10.1007/BFb0115156.

69. Faeder, J.; Ladanyi, B. Molecular Dynamics Simulations of the Interior of Aqueous Reverse Micelles J. Phys. Chem. B; 2000; Vol. 104, pp 1033-1046, https://doi.org/10.1021/jp993076u.

70. D'Aprano, A.; Lizzio, A.; Turco Liveri, V.; Aliotta, F.; Vasi, C.; Migliardo, P. Aggregation states of water in reversed AOT micelles: Raman evidence J. Phys. Chem.; 1988; Vol. 92, pp 4436-4439, doi:10.1021/j100326a038.

71. Rodriguez, J.; Laria, D.; Guardia, E.; Martí, J. Dynamics of water nanodroplets and aqueous protons in non-ionic reverse micelles Phys Chem Chem Phys.; 2009; Vol. 11, pp. 1484-1490, doi: 10.1039/b816827j.

72. Costard, R.; Elsaesser, T. Femtosecond OH Bending Dynamics of Water Nanopools Confined In Reverse Micelles J Phys Chem B.; 2013; Vol. 117, 15338-45, doi: 10.1021/jp403559d.

73. Rosenfeld, D.; A Schmuttenmaer, C. Dynamics of Water Confined Within Reverse Micelles J. Phys. Chem. B; 2006; Vol. 110, pp. 14304-14312, doi: 10.1021/jp060552p.

74. Onori G.; Santucci, A. IR investigations of water structure in Aerosol OT reverse micellar aggregates J. Phys. Chem.; 1993; Vol. 97, pp 5430-5434, doi: 10.1021/j100122a040.

75. Moilanen, D.E.; Fenn, E.E.; Wong, D.; Fayer, M.D. Water Dynamics at the Interface in AOT Reverse Micelles. The Journal of Physical Chemistry B 2009, 113, 8560-8568, doi:10.1021/jp902004r.

76. Marques, B.; Nucci, N.; Dodevski, I.; Wang, K.; A Athanasoula, E.; Jorge, C.; Wand, A. Measurement and Control of $\mathrm{pH}$ in the Aqueous Interior Micelles J. Phys. Chem. B; 2014; Vol. 118, pp 2020-2031, doi:10.1021/jp4103349. 
77. Vodolazkaya, N.A.; McHedlov-Petrossyan, N.O.; Salamanova, N.V.; Surov, Y.N.; Doroshenko, A.O. Molecular spectroscopy studies of solvent properties of dispersed 'water pools': Fluorescein and 2,7dichlorofluorescein in reversed AOT-based microemulsions. Journal of Molecular Liquids 2010, 157, 105112, doi:https://doi.org/10.1016/j.molliq.2010.08.013.

78. El Seoud, O.A.; Chinelatto, A.M.; Shimizu, M.R. Acid-base indicator equilibria in the presence of aerosol-OT aggregates in heptane. Ion exchange in reversed micelles. Journal of Colloid and Interface Science 1982, 88, 420-427, doi:https://doi.org/10.1016/0021-9797(82)90270-3.

79. Crans, D.; Levinger, N. The Conundrum of $\mathrm{pH}$ in Water Nanodroplets: Sensing $\mathrm{pH}$ in Reverse Micelle Water Pools Acc Chem Res. 2012; Vol. 45, pp. 1637-1645, doi: 10.1021/ar200269g.

80. Hasegawa, M.; Sugimura, T.; Suzaki, Y.; Shindo, Y.; Kitahara, A. Microviscosity in Water Pool of AerosolOT Reversed Micelle Determined with Viscosity-Sensitive Fluorescence Probe, Auramine O, and Fluorescence Depolarization of Xanthene Dyes. The Journal of Physical Chemistry 1994, 98, 2120-2124, doi:10.1021/j100059a024.

81. da Graça Miguel, M.; Burrows, H.D.; Escaroupa Pereira, M.A.; Varela, A.P. Probing solute distribution and acid-base behaviour in water-in-oil microemulsions by fluorescence techniques. Colloids and Surfaces A: Physicochemical and Engineering Aspects 2001, 176, 85-99, doi:https://doi.org/10.1016/S09277757(00)00615-4.

82. Levinger, N.E.; Swafford, L.A. Ultrafast Dynamics in Reverse Micelles. Annual Review of Physical Chemistry 2009, 60, 385-406, doi:10.1146/annurev.physchem.040808.090438.

83. Smith, R.; L. Luisi, P. Micellar Solubilization of Biopolymers in Hydrocarbon Solvents III. Empirical Definition of an Acidity Scale in Reverse Micelles, HCA 1980; Vol. 63, pp. 2302-2311, https://doi.org/10.1002/hlca.19800630820.

84. Halliday N. A.; Peet A. C.; Britton M. M. Detection of pH in Microemulsions, without a Probe Molecule, Using Magnetic Resonance J. Phys. Chem. B 2010; Vol. 114, pp. 13745-13751, doi:10.1021/jp108649x.

85. Oshitani, J.; Takashina, S.; Yoshida, M.; Gotoh, K. Water Pool pH of AOT-Based W/O Microemulsions at Various Water Contents Estimated by Absorbance Ratio of Pyranine Journal of Chemical Engineering of Japan 2008; Vol. 41, pp. 507-512, doi: 10.1252/jcej.07we287.

86. Miguel, M.; Burrows, H.; Alice Escaroupa Pereira, M.; Paula Varela, A. Probing solute distribution and acid-base behaviour in water-in-oil microemulsions by fluorescence techniques Colloids and Surfaces A: Physicochemical and Engineering Aspects 2001; Vol. 176, pp. 85-99, https://doi.org/10.1016/S09277757(00)00615-4.

87. Cohen, B.; Huppert, D.; Solntsev, K.; Tsfadia, Y.; Nachliel, E.; Gutman, M. Excited State Proton Transfer in Reverse Micelles J. Am. Chem. Soc. 2002; Vol. 124, pp. 7539-7547, doi:10.1021/ja012646c.

88. Kwon, O.-H.; Jang, D.-J. Excited-State Double Proton Transfer of 7-Azaindole in Water Nanopools. The Journal of Physical Chemistry B 2005, 109, 20479-20484, doi:10.1021/jp053187v.

89. Baruah, B.; Swafford, L.; Crans, D.; Levinger, N. Do Probe Molecules Influence Water in Confinement? J Phys Chem B. 2008; Vol. 112, pp. 10158-10164, doi: 10.1021/jp800390t.

90. Baruah, B.; Roden, J.; Sedgwick, M.; Correa, M.; Crans, D.; Levinger, N. When Is Water Not Water? Exploring Water Confined in Large Reverse Micelles Using a Highly Charged Inorganic Molecular Probe J. Am. Chem. Soc. 2006; Vol. 128, pp. 12758-12765, doi: 10.1021/ja0624319.

91. Stathatos, E.; Lianos, P.; DelMonte, F.; Levy, D.; Tsiourvas, D. Formation of TiO2 nanoparticles in reverse micelles and their deposition as thin films on glass substrates. Langmuir 1997, 13, 4295-4300, doi:10.1021/la9701642.

92. Ebert, H.F.K.N. Determination of $\mathrm{pH}$ in reversed micelles II. Application of the method proposed previously to other reversed micellar systems. Colloid \& Polymer Sci 1982, 260, 697-701, doi:https://doi.org/10.1007/BF01414656.

93. Sedgwick, M.; Crans, D.; Levinger, N. What Is Inside a Nonionic Reverse Micelle? Probing the Interior of Igepal Reverse Micelles Using Decavanadate, Langmuir 2009; Vol. 25, pp. 5496-5503, doi: 10.1021/la8035067.

94. Mukherjee, P.; Gupta, S.; Rafiq, S.; Yadav, R.; Jain, V.K.; Raval, J.; Sen, P. Ramping of pH Across the Water-Pool of a Reverse Micelle. Langmuir 2016, 32, 1693-1699, doi:10.1021/acs.langmuir.5b04429.

95. Pito, D.S.; Fonseca, I.M.; Ramos, A.; Vital, J.; Castanheiro, J.E. Hydrolysis of sucrose using sulfonated poly(vinyl alcohol) as catalyst. Bioresurce Technology 2009; Vol. 100, pp. 4546-4550, https://doi.org/10.1016/j.biortech.2009.04.060. 
96. Hasegawa, M. Buffer-like Action in Water Pool of Aerosol OT Reverse Micelles Langmuir 2001; Vol. 17, pp1426-1431, doi:10.1021/la001336p.

97. Hojo, M.; Ueda, T.; Daike, C.; Takezaki, F.; Furuya, Y.; Miyamoto, K.; Narutaki, A.; Kato, R. Great Enhancement in the Oxidation Ability of Dilute Nitric Acid in Nanoscale Water-Droplets of Reverse Micelle Systems Bull. Chem. Soc. Jpn. 2006; Vol. 79, pp. 1215-1222, https://doi.org/10.1246/bcsj.79.1215.

98. Walde P.; Mao, Q.; Bru, R.; L. Luisi, P.; Kuboi, R. pH artifacts in reverse micellar enzymology: A warning Pure and Applied Chemistry 1992; Vol. 64, pp. 1771-1775, https://doi.org/10.1351/pac199264111771.

99. Küchler, A.; Yoshimoto, M.; Luginbühl, S.; Mavelli, F.; Peter, W. Enzymatic reactions in confined environments Nature Nanotechnology 2016; Vol. 11, pp. 409-420, doi: 10.1038/NNANO.2016.54.

100. Chang G. G.; Huang, T. M.; Hung, H.-C. Reverse micelles as life-mimicking systems Proc Natl Sci Counc Repub China B 2000; Vol. 24, pp. 89-100, ISSN: 0255-6596.

101. Pileni, M.P. Structure and Reactivity in Reverse Micelles; Elsevier: 1989, ISBN-13: 978-0444881663/ISBN10: 0444881662.

102. Pal, N.; Verma, S.D.; Singh, M.; Sen, S. Fluorescence Correlation Spectroscopy: An Efficient Tool for Measuring Size, Size-Distribution and Polydispersity of Microemulsion Droplets in Solution Anal Chem. 2011; Vol. 83, pp. 7736-7744, doi: 10.1021/ac2012637.

103. Bhattacharyya, K. Solvation Dynamics and Proton Transfer in Supramolecular Assemblies Acc. Chem. Res. 2003; Vol. 36, pp. 95-101, doi: 10.1021/ar020067m.

104. Spehr, T.L.; Frick, B.; Zamponi, M.; Stühn, B. Dynamics of water confined to reverse AOT micelles. Soft Matter 2011, 7, 5745-5755, doi:10.1039/C1SM05204G.

105. Fayer, M.D. Water in a Crowd. Physiology 2011, 26, 381-392, doi:10.1152/physiol.00021.2011.

106. Moilanen, D.; Levinger, N.; B Spry, D.; D Fayer, M. Confinement or the Nature of the Interface? Dynamics of Nanoscopic Water J. Am. Chem. Soc. 2007; Vol. 129, pp. 14311-14318, doi: 10.1021/ja073977d.

107. Ellis, R.J.; Minton, A.P. Join the crowd. Nature 2003, 425, 27, doi:10.1038/425027a.

108. Minton, A.P. Implications of macromolecular crowding for protein assembly. Current Opinion in Structural Biology 2000, 10, 34-39, doi:https://doi.org/10.1016/S0959-440X(99)00045-7.

109. Minton, A.P. Influence of excluded volume upon macromolecular structure and associations in 'crowded" media. Current Opinion in Biotechnology 1997, 8, 65-69, doi:https://doi.org/10.1016/S09581669(97)80159-0.

110. Zhou, H.-X.; Rivas, G.; Minton, A. Macromolecular Crowding and Confinement: Biochemical, Biophysical, and Potential Physiological Consequences Annu Rev Biophys 2008; Vol. 37, pp. 375-397, doi: 10.1146/annurev.biophys.37.032807.125817.

111. Zhou, H.-X. Protein Folding in Confined and Crowded Environments Arch Biochem Biophys. $2008 ;$ Vol. 469, pp. 76-82, doi: 10.1016/j.abb.2007.07.013.

112. Zimmerman, S.B.; Minton, A. Macromolecular Crowding: Biochemical, Biophysical, and Physiological Consequences Annu Rev Biophys Biomol Struct. 1993; Vol. 22, pp. 27-65, doi: 10.1146/annurev.bb.22.060193.000331.

113. Murakami, H. Protein and Water Confined in Nanometer-Scale Reverse Micelles Studied by Near Infrared, Terahertz, and Ultrafast Visible Spectroscopies. Advances in Protein Chemistry and Structural Biology 2013; Vol. 93, pp. 183-211, doi: 10.1016/B978-0-12-416596-0.00006-3.

114. Kuznetsova, I. M; Zaslavsky, B.; Breydo, L.; K Turoverov, K.; Uversky, V. Beyond the Excluded Volume Effects: Mechanistic Complexity of the Crowded Milieu Molecules 2015; Vol. 20, pp. 1377-1409, doi: 10.3390/molecules20011377.

115. Bakulin, A.A.; Cringus, D.; Pieniazek, P.A.; Skinner, J.L.; Jansen, T.L.C.; Pshenichnikov, M.S. Dynamics of Water Confined in Reversed Micelles: Multidimensional Vibrational Spectroscopy Study. The Journal of Physical Chemistry B 2013, 117, 15545-15558, doi:10.1021/jp405853j.

116. Quist, P.-O.; Halle, B. Water dynamics and aggregate structure in reversed micelles at sub-zero temperatures. A deuteron spin relaxation study. Journal of the Chemical Society, Faraday Transactions 1: Physical Chemistry in Condensed Phases 1988, 84, 1033-1046, doi:10.1039/F19888401033.

117. Piletic, I.; Tan, H.-S.; D Fayer, M. Dynamics of Nanoscopic Water: Vibrational Echo and Infrared Pump-Probe Studies of Reverse Micelles J. Phys. Chem. B 2005; Vol. 109, pp. 21273-21284, doi: 10.1021/jp051837p. 
118. Harpham, M.; Ladanyi, B.; Levinger, N.; Herwig, K. Water motion in reverse micelles studied by quasielastic neutron scattering and molecular dynamics simulations J Chem Phys. 2004; Vol. 121, pp. 78557868, doi: 10.1063/1.1792592.

119. Abel, S.; Sterpone, F.; Bandyopadhyay, S.; Marchi, M. Molecular Modeling and Simulations of AOT-Water Reverse Micelles in Isooctane: Structural and Dynamic Properties J. Phys. Chem. B 2004; Vol. 108, pp. 19458-19466, doi: 10.1021/jp047138e.

120. Hirose, Y.; Yui, H.; Sawada, T. The ultrafast relaxation dynamics of a viscosity probe molecule in an AOTreversed micelle: Contribution of the specific interactions with the local environment. Journal of Physical Chemistry B 2004, 108, 9070-9076, doi:10.1021/jp0370775.

121. Laage, D.; Hynes, J.T. A Molecular Jump Mechanism of Water Reorientation. Science 2006, 311, 832.

122. Kitchens, C.L.; Bossev, D.P.; Roberts, C.B. Solvent Effects on AOT Reverse Micelles in Liquid and Compressed Alkanes Investigated by Neutron Spin-Echo Spectroscopy. The Journal of Physical Chemistry B 2006, 110, 20392-20400, doi:10.1021/jp063844z.

123. Chattopadhyay, A.; Mukherjee, S.; Raghuraman, H. Reverse micellar organization and dynamics: A wavelength-selective fluorescence approach. Journal of Physical Chemistry B 2002, 106, 13002-13009, doi:10.1021/jp021801m.

124. Piletic, I.R.; Moilanen, D.E.; Spry, D.B.; Levinger, N.E.; Fayer, M.D. Testing the Core/Shell Model of Nanoconfined Water in Reverse Micelles Using Linear and Nonlinear IR Spectroscopy. The Journal of Physical Chemistry A 2006, 110, 4985-4999, doi:10.1021/jp061065c.

125. Fenn, E.E.; Wong, D.B.; Fayer, M.D. Water dynamics in small reverse micelles in two solvents: Twodimensional infrared vibrational echoes with two-dimensional background subtraction. The Journal of Chemical Physics 2011, 134, 054512, doi:10.1063/1.3532542.

126. Dokter, A.M.; Petersen, C.; Woutersen, S.; Bakker, H.J. Vibrational dynamics of ice in reverse micelles. The Journal of Chemical Physics 2008, 128, 044509, doi:10.1063/1.2826376.

127. Dokter, A.; Woutersen, S.; Bakker, H. Inhomogeneous dynamics in confined water nanodroplets PNAS 2006; Vol. 103, pp. 15355-15358, https://doi.org/10.1073/pnas.0603239103.

128. Dokter, A.; Woutersen, S.; Bakker, H. Anomalous Slowing Down of the Vibrational Relaxation of Liquid Water Upon Nanoscale Confinement Phys Rev Lett. 2005; Vol. 94, pp. 178301, doi: 10.1103/PhysRevLett.94.178301.

129. Lipari, G.; Szabo, A. Effect of librational motion on fluorescence depolarization and nuclear magnetic resonance relaxation in macromolecules and membranes. Biophysical Journal 1980, 30, 489-506, doi:https://doi.org/10.1016/S0006-3495(80)85109-5.

130. Tan, H.-S.; Piletic, I.R.; Riter, R.E.; Levinger, N.E.; Fayer, M.D. Dynamics of Water Confined on a Nanometer Length Scale in Reverse Micelles: Ultrafast Infrared Vibrational Echo Spectroscopy. Physical Review Letters 2005, 94, 057405, doi:10.1103/PhysRevLett.94.057405.

131. Ivanov, E.N. Theory of Rotational Brownian Motion J. Exptl. Theoret. Phys. (U.S.S.R.) 1963, 45, pp 15091517 (translation published by the American Institute of Physics), ISBN-ISSN:0038-5646.

132. Senapati, S.; Chandra, A. Dielectric Constant of Water Confined in a Nanocavity. The Journal of Physical Chemistry B 2001, 105, 5106-5109, doi:10.1021/jp011058i.

133. Pollack, G.H. The role of aqueous interfaces in the cell. Advances in Colloid and Interface Science 2003, 103, 173-196, doi:https://doi.org/10.1016/S0001-8686(02)00095-7.

134. Martinek, K.; Klyachko, N.L.; Kabanov, A.V.; Khmelnitsky, Y.L.; Levashov, A.V. Micellar enzymology: its relation to membranology. Biochimica et Biophysica Acta (BBA) - Biomembranes 1989, 981, 161-172, doi:https://doi.org/10.1016/0005-2736(89)90024-2.

135. Siegel, D.P. Inverted micellar structures in bilayer membranes. Formation rates and half-lives. Biophysical Journal 1984, 45, 399-420, doi:https://doi.org/10.1016/S0006-3495(84)84164-8.

136. Vacher, M.; Waks, M.; Nicot, C. Myelin Proteins in Reverse Micelles: Tight Lipid Association Required for Insertion of the Folch-Pi Proteolipid into a Membrane-Mimetic System. Journal of Neurochemistry 1989, 52, 117-123, doi:10.1111/j.1471-4159.1989.tb10905.x.

137. Delahodde, A.; Vacher, M.; Nicot, C.; Waks, M. Solubilization and insertion into reverse micelles of the major myelin transmembrane proteolipid. FEBS Letters 1984, 172, 343-347, doi:10.1016/00145793(84)81154-0. 
138. Bachmann, P.A.; Walde, P.; Luisi, P.L.; Lang, J. Self-replicating micelles: aqueous micelles and enzymatically driven reactions in reverse micelles. Journal of the American Chemical Society 1991, 113, 82048209, doi:10.1021/ja00022a002.

139. Bachmann, P.A.; Walde, P.; Luisi, P.L.; Lang, J. Self-replicating reverse micelles and chemical autopoiesis. Journal of the American Chemical Society 1990, 112, 8200-8201, doi:10.1021/ja00178a073.

140. Doherty, I.D.C.P. Simultaneous Observation of Attractive Interaction, Depletion Forces, and "Sticky" Encounters between AOT Reverse Micelles in Isooctane Using Microelectrode Voltammetry. The Journal of Physical Chemistry B 2000, 104, 8061-8067, doi:DOI: 10.1021/jp9923015.

141. Koper, G.J.M.; Bedeaux, D. The Percus-Yevick approximation for repulsive hard spheres with surface adhesion. Physica A: Statistical Mechanics and its Applications 1992, 187, 489-502, doi:https://doi.org/10.1016/0378-4371(92)90007-D.

142. Jain, T.K.; Cassin, G.; Badiali, J.P.; Pileni, M.P. Relation between Exchange Process and Structure of AOT Reverse Micellar System. Langmuir 1996, 12, 2408-2411, doi:10.1021/la950756p.

143. Sereno, P.G.M.J.S.C.C. Electrochemistry in AOT Reverse Micelles. A Powerful Technique To Characterize Organized Media. J. Phys. Chem. C 2007, 111, 4269-4276, doi:DOI: 10.1021/jp067145y.

144. D'Angelo, M.; Fioretto, D.; Onori, G.; Santucci, A. Micellar interactions in water-in-oil microemulsions. Journal of Molecular Structure 1996, 383, 157-163, doi:https://doi.org/10.1016/S0022-2860(96)09280-0.

145. Doherty, I.C. Voltammetry as a Tool for Monitoring Micellar Structural Evolution? Analytical Chemistry 72(4): 2000, 72, 687-695, doi:DOI: 10.1021/ac990354c.

146. Park, H.-R.; Im, S.-E.; Seo, J.-J.; Bark, K.-M. Spectroscopic Properties of Quercetin in AOT Reverse Micelles Bulletin of the Korean Chemical Society 2014; Vol. 35, pp.828-832, doi: 10.5012/bkcs.2014.35.3.828.

147. Bagwe, R.P.; Khilar, K.C. Effects of intermicellar exchange rate on the formation of silver nanoparticles in reverse microemulsions of AOT. Langmuir 2000, 16, 905-910, doi:10.1021/la980248q.

148. Wang, J. Carbon-nanotube based electrochemical biosensors: A review. Electroanalysis 2005, 17, 7-14, doi:10.1002/elan.200403113.

149. Barnickel, P.; Wokaun, A.; Sager, W.; Eicke, H.F. Size tailoring of silver colloids by reduction in WO microemulsions. Journal of Colloid and Interface Science 1992, 148, 80-90, doi:https://doi.org/10.1016/00219797(92)90116-4.

150. Lisiecki, I.; Pileni, M.P. Synthesis of copper metallic clusters using reverse micelles as microreactors. Journal of the American Chemical Society 1993, 115, 3887-3896, doi:10.1021/ja00063a006.

151. Solla-Gullón, J.; Montiel, V.; Aldaz, A.; Clavilier, J. Electrochemical characterisation of platinum nanoparticles prepared by microemulsion: how to clean them without loss of crystalline surface structure. Journal of Electroanalytical Chemistry 2000, 491, 69-77, doi:https://doi.org/10.1016/S0022-0728(00)00306-5.

152. Chhabra, V.; Pillai, V.; K. Mishra, B.; Morrone, A.; O. Shah, D. Synthesis, Characterization, and Properties of Microemulsion-Mediated Nanophase TiO2 Particles Langmuir 1995; Vol. 11, pp 3307-3311, doi: 10.1021/la00009a007.

153. Osseo-Asare, K.; Arriagada, F.J. Preparation of $\mathrm{SiO} 2$ nanoparticles in a non-ionic reverse micellar system. Colloids and Surfaces 1990, 50, 321-339, doi:https://doi.org/10.1016/0166-6622(90)80273-7.

154. Song, K.C.; Kim, J.H. Preparation of Nanosize Tin Oxide Particles from Water-in-Oil Microemulsions. J Colloid Interface Sci 1999, 212, 193-196, doi:10.1006/jcis.1998.6022.

155. Kida, T.; Guan, G.; Minami, Y.; Ma, T.; Yoshida, A. Photocatalytic hydrogen production from water over a LaMnO3/CdS nanocomposite prepared by the reverse micelle method. Journal of Materials Chemistry 2003, 13, 1186-1191, doi:10.1039/B211812B.

156. Towata, A.; Uwamino, Y.; Sando, M.; Iseda, K.; Taoda, H. Synthesis of titania photocatalysts dispersed with nickel nanosized particles. Nanostructured Materials 1998, 10, 1033-1042, doi:https://doi.org/10.1016/S0965-9773(98)00124-X.

157. Toshiyuki, M.; Kazuyasu, F.; Yumin, P.; Ken-ichi, M.; Gin-ya, A. Carbon Monoxide Oxidation Characteristics Over the Al2O3-supported CeO2-ZrO2 Catalysts Prepared by the Microemulsion Method. Chemistry Letters 1997, 26, 1285-1286, doi:10.1246/cl.1997.1285.

158. López-Quintela, M.A.; Tojo, C.; Blanco, M.C.; García Rio, L.; Leis, J.R. Microemulsion dynamics and reactions in microemulsions. Current Opinion in Colloid $\mathcal{E}$ Interface Science 2004, 9, 264-278, doi:https://doi.org/10.1016/j.cocis.2004.05.029. 
159. Bommarius, A.S.; Holzwarth, J.F.; Wang, D.I.C.; Hatton, T.A. Coalescence and solubilizate exchange in a cationic four-component reversed micellar system. The Journal of Physical Chemistry 1990, 94, 7232-7239, doi:10.1021/j100381a051.

160. Zhang, J.; Han, B.; Liu, J.; Zhang, X.; He, J.; Liu, Z.; Jiang, T.; Yang, G. Recovery of Silver Nanoparticles Synthesized in AOT/C12E4 Mixed Reverse Micelles by Antisolvent CO2. Chemistry - A European Journal 2002, 8, 3879-3883, doi:doi:10.1002/1521-3765(20020902)8:17<3879::AID-CHEM3879>3.0.CO;2-W.

161. Borsarelli, C.D.; Braslavsky, S.E. The partial molar volume of the proton in water determined by laserinduced optoacoustic studies. Journal of Photochemistry and Photobiology B: Biology 1998, 43, 222-228, doi:https://doi.org/10.1016/S1011-1344(98)00112-2.

162. Dutta, P.K.; Jakupca, M.; Reddy, K.S.N.; Salvati, L. Controlled growth of microporous crystals nucleated in reverse micelles. Nature 1995, 374, 44, doi:10.1038/374044a0.

163. Steigerwald, M.L.; Alivisatos, A.P.; Gibson, J.M.; Harris, T.D.; Kortan, R.; Muller, A.J.; Thayer, A.M.; Duncan, T.M.; Douglass, D.C.; Brus, L.E. Surface derivatization and isolation of semiconductor cluster molecules. Journal of the American Chemical Society 1988, 110, 3046-3050, doi:10.1021/ja00218a008.

164. Chen, D.-H.; Wu, S.-H. Synthesis of Nickel Nanoparticles in Water-in-Oil Microemulsions. Chemistry of Materials 2000, 12, 1354-1360, doi:10.1021/cm991167y.

165. Moreira Ferreira, L.; Dutra de Souza, F.; Nome Aguilera, F.J.; Cruz Vieira, I. Electrochemical sensor based on rhodium nanoparticles stabilized in zwitterionic surfactant for p-coumaric acid analysis. Canadian Journal of Chemistry 2016, 95, 113-119, doi:10.1139/cjc-2016-0338.

166. Zapp, E.; Souza, F.D.; Souza, B.S.; Nome, F.; Neves, A.; Vieira, I.C. A bio-inspired sensor based on surfactant film and Pd nanoparticles. The Analyst 2013, 138, 509-517, doi:10.1039/c2an36264c.

167. Cadorin Fernandes, S.; Dutra de Souza, F.; Silveira de Souza, B.; Nome, F.; Cruz Vieira, I. Gold nanoparticles dispersed in zwitterionic surfactant for peroxidase immobilization in biosensor construction. Sensors and Actuators B: Chemical 2012, 173, 483-490, doi:https://doi.org/10.1016/j.snb.2012.07.054.

168. Yuasa, M.; Masaki, T.; Kida, T.; Shimanoe, K.; Yamazoe, N. Nano-sized PdO loaded SnO2 nanoparticles by reverse micelle method for highly sensitive CO gas sensor. Sensors and Actuators B: Chemical 2009, 136, 99-104, doi:https://doi.org/10.1016/j.snb.2008.11.022.

169. Matsushima, S.; Yasutake, T.; Norio, M.; Noboru, Y. Electronic Interaction between Metal Additives and Tin Dioxide in Tin Dioxide-Based Gas Sensors. Japanese Journal of Applied Physics 1988, 27, 1798, doi:10.1143/JJAP.27.1798.

170. Shigenori, M.; Jun, T.; Norio, M.; Noboru, Y. TEM Observation of the Dispersion State of Pd on SnO2. Chemistry Letters 1989, 18, 1651-1654, doi:10.1246/cl.1989.1651.

171. Yuasa, M.; Sakai, G.; Shimanoe, K.; Teraoka, Y.; Yamazoe, N. Reverse Micelle-Based Preparation of Carbon-Supported La1-x Sr x Mn1-y Fe y O3+ $\delta$ for Oxygen Reduction Electrode. Journal of The Electrochemical Society 2004, 151, A1690-A1695, doi:10.1149/1.1789156.

172. Yuasa, M.; Shimanoe, K.; Teraoka, Y.; Yamazoe, N. Preparation of carbon-supported nano-sized LaMnO3 using reverse micelle method for energy-saving oxygen reduction cathode. Catalysis Today 2007, 126, 313319, doi:https://doi.org/10.1016/j.cattod.2007.06.006.

173. Sato, T.; Uno, S.; Hashizume, T.; Hasegawa, H. Large Schottky Barrier Heights on Indium PhosphideBased Materials Realized by In-Situ Electrochemical Process Japanese Journal of Applied Physics 1997; Vol. 36, pp. 1811-1817, doi: 10.1143/JJAP.36.1811.

174. Kimura T.; Hideki, H.; Taketomo, S.; Tamotsu, H. Sensing Mechanism of InP Hydrogen Sensors Using Pt Schottky Diodes Formed by Electrochemical Process. Japanese Journal of Applied Physics 2006, 45, 3414, doi: 10.1143/JJAP.45.3414.

175. Grym, J.; Prochazkova, O.; Yatskiv, R.; Piksova, K. Hydrogen sensors based on electrophoretically deposited Pd nanoparticles onto InP. Nanoscale Research Letters 2011, 6, 5, doi:10.1186/1556-276x-6-392.

176. Zdansky, K. Highly sensitive hydrogen sensor based on graphite-InP or graphite-GaN Schottky barrier with electrophoretically deposited Pd nanoparticles. Nanoscale Research Letters 2011, 6, 490, doi:10.1186/1556-276x-6-490.

177. Davarpanah, S.J.; Karimian, R.; Goodarzi, V.; Piri, F. Synthesis of Copper (II) Oxide (CuO) Nanoparticles and Its Application as Gas Sensor. Journal of Applied Biotechnology Reports 2016, V 322, pp 329-332, ISSN: 2423-5784. 
178. Guliants, E.A.; Schwarb, R.; Bearbower, H.; Gord, J.R.; Bunker, C.E. Functional nanoparticles in thin films as sensing media. Reviews on Advanced Materials Science 2005, 10, 289-294, ISSN: 1606-5131.

179. Kalantar-zadeh, K.; Fry, B.N. Inorganic Nanotechnology Enabled Sensors. In Nanotechnology-Enabled Sensors, Springer US: Boston, MA, 2008; pp. 283-370, https://doi.org/10.1007/978-0-387-68023-1_6.

180. Collins, P.G.; Arnold, M.S.; Avouris, P. Engineering carbon nanotubes and nanotube circuits using electrical breakdown. Science 2001, 292, 706-709, doi:10.1126/science.1058782.

181. Avouris, P. Carbon nanotube electronics. Chemical Physics 2002, 281, 429-445, doi:https://doi.org/10.1016/S0301-0104(02)00376-2.

182. Hu, J.; Ouyang, M.; Yang, P.; Lieber, C.M. Controlled growth and electrical properties of heterojunctions of carbon nanotubes and silicon nanowires. Nature 1999, 399, 48, doi:10.1038/19941.

183. Dai, H.; Hafner, J.H.; Rinzler, A.G.; Colbert, D.T.; Smalley, R.E. Nanotubes as nanoprobes in scanning probe microscopy. Nature 1996, 384, 147, doi:10.1038/384147a0.

184. Wiedwald, U.; Han, L.Y.; Biskupek, J.; Kaiser, U.; Ziemann, P. Preparation and characterization of supported magnetic nanoparticles prepared by reverse micelles. Beilstein Journal of Nanotechnology 2010, 1, 24-47, doi:10.3762/bjnano.1.5.

185. McQuade, D.T.; Pullen, A.E.; Swager, T.M. Conjugated Polymer-Based Chemical Sensors. Chemical Reviews 2000, 100, 2537-2574, doi:10.1021/cr9801014.

186. Albert, K.J.; Lewis, N.S.; Schauer, C.L.; Sotzing, G.A.; Stitzel, S.E.; Vaid, T.P.; Walt, D.R. Cross-Reactive Chemical Sensor Arrays. Chemical Reviews 2000, 100, 2595-2626, doi:10.1021/cr980102w.

187. Swager, T.M. The Molecular Wire Approach to Sensory Signal Amplification. Accounts of Chemical Research 1998, 31, 201-207, doi:10.1021/ar9600502.

188. Jang, J.; Yoon, H. Facile fabrication of polypyrrole nanotubes using reverse microemulsion polymerization. Chemical Communications 2003, 720-721, doi:10.1039/b211716a.

189. Jang, J.; Yoon, H. Formation mechanism of conducting polypyrrole nanotubes in reverse micelle systems. Langmuir 2005, 21, 11484-11489, doi:10.1021/la051447u.

190. Zhang, X.Y.; Goux, W.J.; Manohar, S.K. Synthesis of polyaniline nanofibers by "nanofiber seeding". Journal of the American Chemical Society 2004, 126, 4502-4503, doi:10.1021/ja031867a.

191. Yoon, H.; Chang, M.; Jang, J. Formation of 1D poly(3,4-ethylenedioxythiophene) nanomaterials in reverse microemulsions and their application to chemical sensors. Advanced Functional Materials 2007, 17, 431-436, doi:10.1002/adfm.200600106.

192. Murphy, C.J. Optical sensing with quantum dots. Analytical Chemistry 2002, 74, 520A-526A, doi:10.1021/ac022124v.

193. Empedocles, S.; Bawendi, M. Spectroscopy of Single CdSe Nanocrystallites. Accounts of Chemical Research 1999, 32, 389-396, doi:10.1021/ar9501939.

194. Kuno, M.; Lee, J.K.; Dabbousi, B.O.; Mikulec, F.V.; Bawendi, M.G. The band edge luminescence of surface modified CdSe nanocrystallites: Probing the luminescing state. The Journal of Chemical Physics 1997, 106, 9869-9882, doi:10.1063/1.473875.

195. Marin, S.; Merkoci, A. Direct electrochemical stripping detection of cystic-fibrosis-related DNA linked through cadmium sulfide quantum dots. Nanotechnology 2009, 20, 055101, doi:10.1088/09574484/20/5/055101.

196. Brown, L.O.; Hutchison, J.E. Controlled growth of gold nanoparticles during ligand exchange. Journal of the American Chemical Society 1999, 121, 882-883, doi:10.1021/ja983510q.

197. Ershov, B.G.; Sukhov, N.L.; Janata, E. Formation, Absorption Spectrum, and Chemical Reactions of Nanosized Colloidal Cobalt in Aqueous Solution. The Journal of Physical Chemistry B 2000, 104, 6138-6142, doi:10.1021/jp000608u.

198. Murray, C.B.; Norris, D.J.; Bawendi, M.G. Synthesis and characterization of nearly monodisperse CdE (E = sulfur, selenium, tellurium) semiconductor nanocrystallites. Journal of the American Chemical Society 1993, 115, 8706-8715, doi:10.1021/ja00072a025.

199. Guzelian, A.A.; Katari, J.E.B.; Kadavanich, A.V.; Banin, U.; Hamad, K.; Juban, E.; Alivisatos, A.P.; Wolters, R.H.; Arnold, C.C.; Heath, J.R. Synthesis of Size-Selected, Surface-Passivated InP Nanocrystals. The Journal of Physical Chemistry 1996, 100, 7212-7219, doi:10.1021/jp953719f.

200. Rockenberger, J.; Scher, E.C.; Alivisatos, A.P. A New Nonhydrolytic Single-Precursor Approach to Surfactant-Capped Nanocrystals of Transition Metal Oxides. Journal of the American Chemical Society 1999, 121, 11595-11596, doi:10.1021/ja993280v. 
201. Trentler, T.J.; Denler, T.E.; Bertone, J.F.; Agrawal, A.; Colvin, V.L. Synthesis of TiO2 Nanocrystals by Nonhydrolytic Solution-Based Reactions. Journal of the American Chemical Society 1999, 121, 1613-1614, doi:10.1021/ja983361b.

202. Penner, R.M. Hybrid electrochemical/chemical synthesis of quantum dots. Accounts of Chemical Research 2000, 33, 78-86, doi:10.1021/ar9702839.

203. Tonucci, R.J.; Justus, B.L.; Campillo, A.J.; Ford, C.E. NANOCHANNEL ARRAY GLASS. Science 1992, 258, 783-785, doi:10.1126/science.258.5083.783.

204. Merkoci, A.; del Valle, M.; Alegret, S. Bionanostructures and their integration into electrochemical sensing system. A review of DNA applications. Revista Mexicana De Fisica 2006, 52, 1-5, ISSN 0035-001X.

205. Dubertret, B.; Skourides, P.; Norris, D.J.; Noireaux, V.; Brivanlou, A.H.; Libchaber, A. In vivo imaging of quantum dots encapsulated in phospholipid micelles. Science 2002, 298, 1759-1762, doi:10.1126/science.1077194.

206. Wang, J.; Liu, G.D.; Rivas, G. Encoded beads for electrochemical identification. Analytical Chemistry 2003, 75, 4667-4671, doi:10.1021/ac034411k. 